\title{
Role of the atmospheric mean state on the initiation of the Madden-Julian oscillation in a tropical channel model
}

\author{
Pallav Ray $\cdot$ Chidong Zhang $\cdot$ Mitchell W. Moncrieff • \\ Jim Dudhia $\cdot$ Julie M. Caron $\cdot$ L. Ruby Leung • \\ Cindy Bruyere
}

Received: 29 April 2009/Accepted: 24 May 2010/Published online: 8 June 2010

(C) Springer-Verlag 2010

\begin{abstract}
Tropical channel models, defined as models that are global in the zonal direction but bounded in the meridional direction, are particularly useful for simulating the Madden-Julian oscillation (MJO) and understanding its physical and dynamical basis. Influences from the extratropics through the lateral boundaries have been found to be essential to the reproduction of the initiation of certain MJO events. This led to a hypothesis that multi-year simulations using a tropical channel model would reproduce reasonable MJO statistics under the influence of prescribed lateral boundary conditions derived from global reanalyses. Interestingly, the MJO statistics in such a multi-year simulation by a high-resolution tropical channel model are not better than those from global climate models. The error in the atmospheric mean state is found to be a possible reason for the poor MJO statistics in the simulation. Nevertheless, even with a large error in the mean state, the multi-year simulation captures two MJO events previously found to be initiated by extratropical influences. However, the model does not reproduce a third event, whose initiation is not directly influenced by the extratropics. This implies that in the absence of dynamical interactions between the MJO and the lateral boundary conditions, the error in the mean
\end{abstract}

P. Ray $(\bowtie) \cdot$ C. Zhang

RSMAS/MPO, University of Miami, 4600 Rickenbacker

Causeway, Miami, FL 33149, USA

e-mail: pray@rsmas.miami.edu

M. W. Moncrieff · J. Dudhia - J. M. Caron - C. Bruyere

National Center for Atmospheric Research,

Boulder, CO 80301, USA

L. Ruby Leung

Pacific Northwest National Laboratory,

Richland, WA 99352, USA state could be sufficient to prevent the MJO initiation. To explore this third MJO event further, a series of sensitivity tests are conducted. These tests show that the simulation of this event is neither critically influenced by the cumulus parameterization employed, nor the initial conditions when the model is integrated 2 weeks prior to the MJO initiation. The model captures this event when the MJO signal is already present in the initial conditions. The use of highresolution sea surface temperature does not improve the simulation of the third MJO event. A higher-resolution nested domain covering the Indo-Pacific warm pool region and including a cloud-system resolving domain over the Indonesian Maritime Continent has little effect on the MJO initiation over the Indian Ocean. In $<2$ weeks the error in the simulation is comparable to the climate error. The role of the simulated MJO on the mean state is also explored. Implications and limitations of these results are discussed.

Keywords Madden-Julian oscillation ·

Intraseasonal variability $\cdot$ Mean state .

Extratropical influence $\cdot$ Tropical channel model

\section{Introduction}

The Madden-Julian oscillation (MJO; Madden and Julian $1971,1972)$ is a dominant feature of intraseasonal (20-90 day) variability in the tropical atmosphere. The oscillation is most prominent over the Indian and western Pacific Oceans, and involves large-scale patterns in atmospheric circulation, and tropical waves coupled to deep convection. Convective coupling diminishes in the eastern Pacific in the presence of the lower sea surface temperature (SST). The MJO has been the subject of intense research because it tests our understanding of the tropical 
circulation, and because of its apparent relationship with other meteorological phenomena in the tropics and beyond (see Lau and Waliser 2005; Zhang 2005). While these studies have improved our knowledge of the MJO over the past decades, accurate numerical simulations of the MJO remain a challenge. Most models do not quantitatively reproduce the observed spatio-temporal scales of the MJO, nor its initiation.

Previous modeling studies typically use: (1) simplified/ analytical approaches (e.g., Blade and Hartmann 1993; Wang and Li 1994; Majda and Biello 2004; Moncrieff 2004; Wedi and Smolarkiewicz 2010); (2) physically more complex atmospheric global climate models (GCMs; Maloney and Hartman 2001; Inness and Slingo 2003), coupled atmosphere-ocean GCMs (Sperber et al. 2005; Pegion and Kirtman 2008a, b); and numerical weather prediction models (Vitart et al. 2007; Woolnough et al. 2007; Agudelo et al. 2009); (3) a cloud-system resolving model with a regional domain (Grabowski and Moncrieff 2001) and the global domain (Miura et al. 2007); (4) a regional mesoscale model (Gustafson and Weare 2004a, b; Monier et al. 2009), and a tropical channel model (TCM; Ray et al. 2009, hereafter R09; Ray and Zhang 2010, hereafter RZ10).

Each category of model has advantages and disadvantages in terms of area coverage, spatial resolution, and the realism of parameterizations of the physical processes, i.e., convection, radiation, planetary boundary layer, and surface exchange. Most models underestimate the strength of the intraseasonal variability and fail to capture its seasonality. The performances of recent GCMs in capturing the MJO were documented by Lin et al. (2006) and Zhang et al. (2006). These studies showed that numerical simulation of the MJO is difficult, and large differences may arise with subtle differences between the models. There are several examples of improved MJO reproduction by changing the physical process parameterization, but the reason for improvement is not always well understood and the improvements may not be robust. Changes to resolution (e.g., Inness et al. 2001), convective parameterizations (e.g., Maloney and Hartman 2001), inclusion of oceanatmosphere feedback (e.g., Zheng et al. 2004), are common examples.

The objective of this paper is to investigate the role of the atmospheric mean state on the initiation of the MJO using a high-resolution TCM. The main advantage of a TCM compared to a regular regional model is that, without east-west boundaries, it isolates the external influences arriving solely from the extratropics. The added constraint provided by the lateral boundary conditions is expected to improve the simulated MJO statistics. Taking this advantage, Gustafson and Weare $(2004 \mathrm{a}$, b) adopted a regular regional model to simulate the MJO over a 2-year period, which yielded reasonable MJO statistics. We use a TCM to examine MJO statistics and individual MJO events. We also use a similar TCM incorporating a different mesoscale model (see Sect. 2.1). Following R09, the initiation of the MJO is defined as the initiation of intraseasonal westerly wind anomalies over the Indian Ocean, irrespective of whether or not it is preceded by a previous event. Occasional references are given with respect to precipitation $(\mathrm{P})$ and humidity.

The error in the mean state is found to be the primary reason for the unsatisfactory MJO statistics in our simulations. This aspect was previously explored using GCMs (e.g., Slingo et al. 1996; Inness et al. 2003; Maloney and Hartman 2001; Ajayamohan and Goswami 2007; Maloney 2009), observations (Zhang and Dong 2004), and modelobservation comparison (Zhang et al. 2006). It was found that the realistic distributions of lower-tropospheric zonal wind and specific humidity, boundary-layer moisture convergence, and precipitation in models were necessary for them to reproduce realistic statistics of the intraseasonal variability. However, the effects of the mean state on the individual MJO events have not been studied previously.

We go one step further by asking: Does the error in the mean state affect all MJO events in a similar way? Is it possible to overcome this deficiency through dynamical control exerted by the meridional boundary conditions? To address these questions, we select three MJO events (see Sect. 2.2) within a time period from which MJO statistics are constructed. Two of them were previously found to be initiated by extratropical influences. R09 showed that simulated MJO initiation in zonal winds of these two observed events did not critically depend on detailed characteristics of the SST, the initial conditions, the latitudinal location of the lateral boundaries, and latent heating and moist processes. The time varying lateral boundary conditions from a global reanalysis was the only factor found to be responsible for the reproduction of the MJO initiation. The mechanism of the MJO initiation for these two events were explored by RZ10, who found the importance of meridional advection of westerly momentum from the extratropics in the generation of lower tropospheric westerlies in the tropics associated with the MJO initiation.

Interestingly, the model in the present study simulates these two MJO events (after years from the start of the model integration) even with a large error in the mean state. The third event is completely missed by the multiyear simulation. In order to quantify causality for the poor simulation of this MJO event, we adopt a case study approach in which we conduct a series of sensitivity tests to investigate the effects of various factors, such as highresolution inner domains, cumulus parameterization, initial conditions, and SST. The error in the mean state, possibly due to cumulus parameterization, is found to be crucial in 
preventing the simulation of this MJO event in the absence of dynamic control from the lateral boundaries. When the MJO statistics are considered, the mean state refers to a climatological or a seasonal mean. When the model is integrated for just few weeks covering an individual MJO event, the model mean state is over the integration time (e.g., 1 month). In the sense that the "weather bias" and "climate bias" are found to be very similar (Boyle et al. 2008), this distinction is somewhat moot.

Section 2 provides a brief description of the model, configurations of the numerical simulations, methods, and data used to constrain and validate the simulations. Section 3 presents the effects of the mean state on the MJO statistics and individual MJO events. Section 4 describes a series of sensitivity tests. The effects of the error growth in the simulations are explored in Sect. 5. Further discussions of the results, their implications and limitations are in Sect. 6, followed by conclusions in Sect. 7 .

In summary, the error in the mean state is found to be important (relatively unimportant) for the initiation of the $\mathrm{MJO}$, in absence (presence) of dynamical control from the meridional boundary conditions. In other words, the dynamical influences emanating from the lateral boundaries can sometimes overcome the negative effects of errors in the mean state on the initiation of the MJO.

\section{Model and data}

\subsection{Model}

A nested regional climate model (NRCM, http://www. nrcm.ucar.edu) was recently developed at the National Center for Atmospheric Research (NCAR) based on the Weather Research and Forecasting (WRF) model. A tropical channel model (TCM) is a particular type of NRCM whose computational domain is global (periodic) in the zonal direction and bounded in the meridional direction.
TCMs have two major advantages for the simulation of zonally low-wavenumber phenomena such as the MJO: (1) the need for lateral boundary conditions in the zonal direction is eliminated; (2) the need for lateral boundary conditions in the meridional direction can be turned to advantage, namely quantifying the effects on MJO initiation by extratropical disturbances propagating into the tropics.

We use the WRF-based TCM in our investigations of the MJO initiation. Conceptually, the configuration is similar to the TCM developed at the University of Miami based on the fifth-generation Pennsylvania State University-NCAR Mesoscale Model (MM5), known as the Tropical MM5 (TMM5, Ray 2008; R09). The horizontal grid-spacing of the WRF-based TCM is $36 \mathrm{~km}$, and the meridional boundaries are placed at $30^{\circ} \mathrm{S}$ and $45^{\circ} \mathrm{N}$. The model top is at $50 \mathrm{hPa}$, and 35 vertical levels are used. Output is archived every $3 \mathrm{~h}$. The configuration of the NRCM used in this study is shown in Fig. 1. The inner domains have grid-spacings of $12 \mathrm{~km}$ (domain D2 in Fig. 1) and $4 \mathrm{~km}$ (D3 in Fig. 1) respectively, and they are located over the warm pool region of the Indian and west Pacific Oceans. Two-way interactions occur between the domains in the nested simulations. No cumulus parameterization is applied in the $4 \mathrm{~km}$ (cloud-system resolving) domain. A larger domain $\left(45^{\circ} \mathrm{S}-45^{\circ} \mathrm{N}\right)$ with higher vertical resolution (51 levels) and model top at $10 \mathrm{hPa}$ is also integrated for several years.

Preliminary simulations are performed over the maritime continent to evaluate the skill of the NRCM simulations against observations and reanalyses. Based on these tests, the suite of parameterizations selected for this study are: Kain-Fritsch cumulus parameterization (KF, Kain 2004), WSM6 cloud microphysics (Hong et al. 2004), CAM 3.0 radiation scheme (Collins et al. 2006), YSU boundary layer scheme (Hong et al. 2006), and Noah land surface model (Chen and Dudhia 2001). A modified BettsMiller (BM, Janjic 1994) scheme is also used to perform a

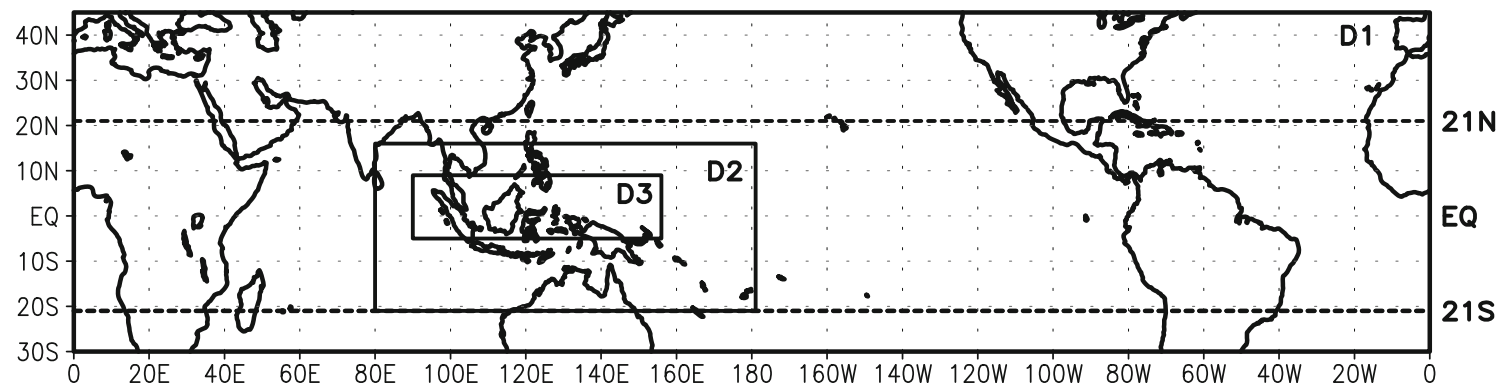

Fig. 1 Model domains for the NRCM $\left(D 10^{\circ}-360^{\circ}, 30^{\circ} \mathrm{S}-45^{\circ} \mathrm{N}\right)$ and the nested domains (D2 $79^{\circ}-183^{\circ} \mathrm{E}, 21^{\circ} \mathrm{S}-16^{\circ} \mathrm{N}$ and $D 390^{\circ}-157^{\circ} \mathrm{E}$, $\left.6^{\circ} \mathrm{S}-10^{\circ} \mathrm{N}\right)$. Domains $D 1, D 2$, and $D 3$ have resolutions of 36,12 and $4 \mathrm{~km}$, respectively. The simulation from 1996 to 2000 includes only the outer domain. The southern boundary was further moved to $45^{\circ} \mathrm{S}$ for the simulation from 1 December 1999 to 1 January 2006. The domain for the TMM5 has resolution of $111 \mathrm{~km}$, and marked by the dashed lines $\left(0^{\circ}-360^{\circ}, 21^{\circ} \mathrm{S}-21^{\circ} \mathrm{N}\right)$. One TMM5 simulation has the same domain as $D 1$. See the text and Tables 1, 2, 3 for further details 

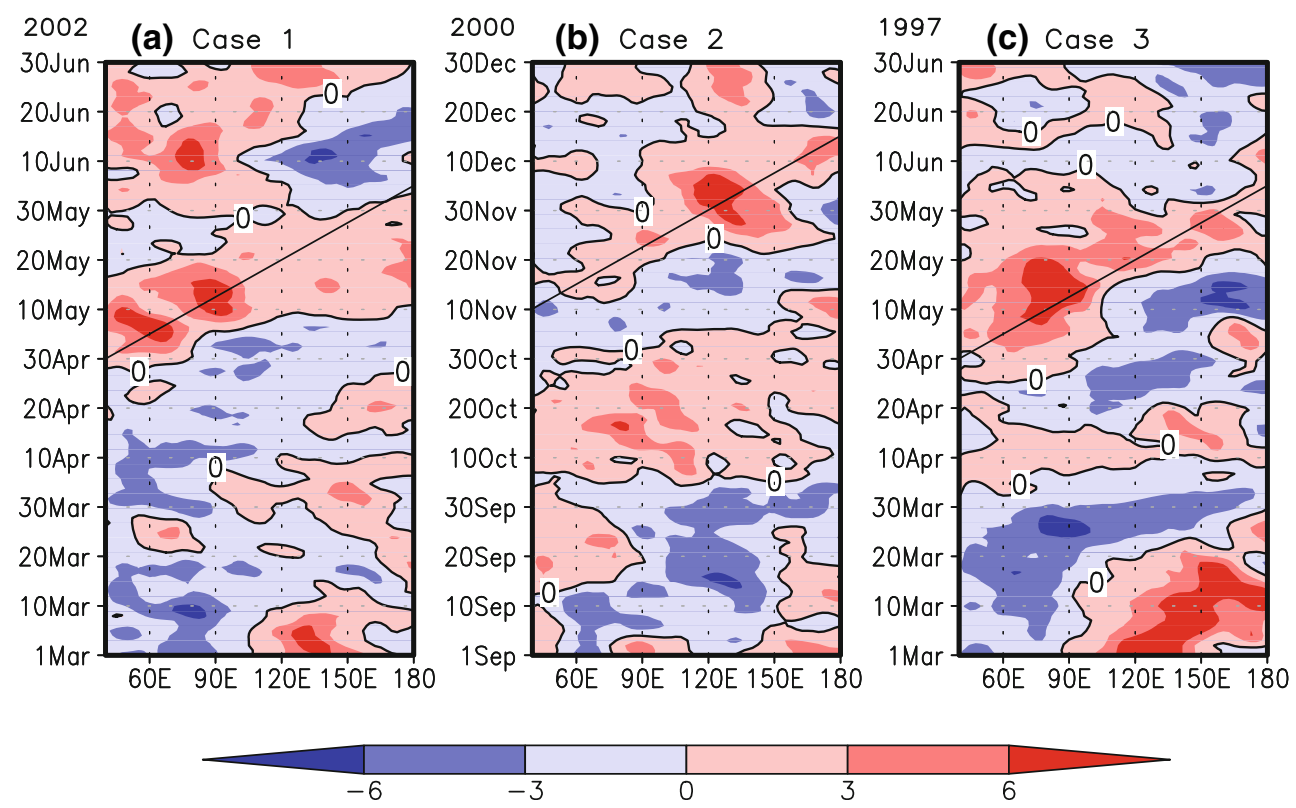

Fig. 2 Time-longitude diagrams of daily anomalies of 850-hPa zonal wind U850 $\left(\mathrm{m} \mathrm{s}^{-1}\right.$, averaged over $10^{\circ} \mathrm{S}-10^{\circ} \mathrm{N}, 3$-day running mean) from the NCEP-NCAR reanalysis for a Case 1, b Case 2, and $\mathbf{c}$ Case

sensitivity tests for the NRCM. A different set of schemes is used in TMM5 for the MJO simulations based on results from more than thirty experiments.

\subsection{Experimental design and method}

The overall approach is to diagnose MJO statistics as well as individual MJO events simulated by the NRCM. Several simulations (multi-year or shorter) are conducted to identify and understand problems in MJO reproduction. We are particularly interested in the model's performance in capturing three individual MJO events. They were in April-May 2002 (Case 1), November-December 2000 (Case 2), and April-May 1997 (Case 3), respectively.

For Case 1 (Fig. 2a), the U850 over the Indian Ocean propagated at a speed slightly faster than the average MJO phase speed $\left(5 \mathrm{~m} \mathrm{~s}^{-1}\right.$, marked by the straight line in Fig. 2). However, the propagation speed over the west Pacific was much faster. Therefore, Case 1 can be considered as a combination of an MJO over the Indian Ocean and (perhaps) a convectively coupled Kelvin wave (Straub and Kiladis 2002) over the western Pacific.

Case 2 (Fig. 2b) was a classic MJO event in terms of location and propagation that occurred during the prime season for the MJO (Salby and Hendon 1994). The initiations of the MJO events in Cases 1 and 2 were found by R09 and RZ10 to be strongly influenced by extratropical forcing. Therefore, one would expect the NRCM to be able to capture these two events when forced by realistic (reanalysis-based) lateral boundary conditions.
3. The MJO events selected in this study are marked by the straight lines whose slope corresponds to an eastward-propagation speed of $5 \mathrm{~m} \mathrm{~s}^{-1}$

The third MJO event occurred during April-May 1997 (Case 3, Fig. 2c). This event started around end of April, and anomalies in lower tropospheric zonal wind and precipitation propagated from the western Indian Ocean to the western Pacific at a speed of about $5 \mathrm{~m} \mathrm{~s}^{-1}$. This event was followed shortly by a strong ENSO event in the summer. Cases 1 and 3 occurred in boreal spring in which the MJO is closest to the equator but on average weaker than in other seasons (Zhang and Dong 2004). All three events show a characteristic intraseasonal transition from low-level easterlies to westerlies. According to Matthews (2008), all three cases considered here are 'successive' MJO events (i.e., preceded by a prior MJO event). Matthews also found in his composite study that the 'successive' events are systematically influenced by the extratropics. However, our analyses of Case 3 using a reanalysis dataset did not reveal any evidence of extratropical influence through the lateral boundaries at the initiation time of this MJO event.

The simulations using the NRCM are listed in Tables 1 and 2. The simulation 1DOM in Table 1 is used to document the MJO statistics in the NRCM, and also to verify its ability to simulate individual MJO events. To extract the MJO signal, a singular vector decomposition (SVD) is applied to U850 and P. This method considers the windprecipitation coupling associated with the MJO. The leading modes are selected based on the North et al. (1982) rule. Three leading modes are found for both observations and model, and they explain $41 \%$ and $31 \%$ of the covariance for the reanalysis and the NRCM, respectively. These selected modes represent the intraseasonal coupled 
components between U850 and P. Time series of U850 and $P$ reconstructed through linear regression of intraseasonal bandpass filtered U850 and P upon their selected leading SVD modes, are considered to represent the MJO.

A similar multi-year simulation (1DOM_2 in Table 1) is also considered to evaluate its skill in capturing Case 1. Two other experiments (2DOM and 3DOM in Table 1) are made to document the effect of increases in the horizontal resolution over the Indo-Pacific warm pool region on MJO initiation.

We also diagnose multi-month simulations of Case 3 to document the sensitivity of MJO initiation to cumulus parameterizations (i.e., BM, NO_cumulus, May1_KF, May1_BM, Apr15_KF, Apr15_BM in Table 2), initial conditions (i.e., May1_KF, Apr15_KF, Apr16_KF in Table 2) and SST (i.e., 98SST, Dy_diur_SST, Diur_SST). The simulations using TMM5 are described in Table 3. Simulations
TMM5_1 and TMM5_2 were previously used by R09 and RZ10 to document the initiation mechanism for Cases 1 and 2 , respectively. The third simulation, TMM5_3 for Case 3, is conducted with the same configuration as the NRCM except the Betts-Miller (Betts and Miller 1986) scheme was used in place of the Kain-Fritsch cumulus parameterization. Note that the Betts-Miller scheme (Betts and Miller 1986) available within the MM5 is different from the Betts-Miller scheme (Janjic 1994) available within the NRCM.

\subsection{Data}

The initial and boundary conditions of the NRCM are from the National Centers for Environmental Prediction-NCAR (NCEP-NCAR) $\mathrm{Re}$-analysis $\left(2.5^{\circ} \times 2.5^{\circ}, 6\right.$-h; Kalnay et al. 1996). The SST data for $1 \mathrm{DOM}$ is from atmospheric model intercomparison project (AMIP; $1^{\circ} \times 1^{\circ}$, 6-h;

Table 1 The multi-year NRCM simulations including the nested runs

\begin{tabular}{|c|c|c|c|c|}
\hline Experiment & Integration time & $\begin{array}{l}\text { Cumulus } \\
\text { scheme }\end{array}$ & Description & Purpose \\
\hline $1 \mathrm{DOM}$ & $\begin{array}{l}1 \text { January } 1996-1 \\
\text { January } 2001\end{array}$ & KF & $\begin{array}{l}\text { 1-way nested from NCEP-NCAR reanalysis } \\
\text { with lateral boundaries at } 30^{\circ} \mathrm{S} \text { and } 45^{\circ} \mathrm{N}\end{array}$ & Diagnosis of MJO statistics \\
\hline 1DOM_2 & $\begin{array}{l}1 \text { December } 1999-1 \\
\text { January } 2006\end{array}$ & $\mathrm{KF}$ & $\begin{array}{l}\text { Same as } 1 \mathrm{DOM} \text {, but with lateral boundaries } \\
\text { at } 45^{\circ} \mathrm{S} \text { and } 45^{\circ} \mathrm{N}\end{array}$ & $\begin{array}{l}\text { Same as } 1 \mathrm{DOM} \text {, but with lateral boundaries at } \\
\text { different locations }\end{array}$ \\
\hline 2DOM & $\begin{array}{l}1 \text { January } 1996-12 \\
\text { February } 1998\end{array}$ & KF & 2-way nested domains $(36 \mathrm{~km} / 12 \mathrm{~km})$ & $\begin{array}{l}\text { Sensitivity due to higher- resolution nested } \\
\text { domain over the Indo-Pacific warm pool }\end{array}$ \\
\hline 3DOM & $\begin{array}{l}1 \text { January } 1997-1 \\
\text { July } 1997\end{array}$ & $\begin{array}{l}\text { KF, No } \\
\text { cumulus }\end{array}$ & $\begin{array}{l}\text { 2-way nested domains }(36 \mathrm{~km} / 12 \mathrm{~km} / 4 \mathrm{~km}) \text {. } \\
\text { Warm start. } 4 \mathrm{~km} \text { domain is cloud resolving }\end{array}$ & $\begin{array}{l}\text { Same as } 2 \mathrm{DOM} \text {, but with cloud-resolving domain } \\
\text { over the maritime continent }\end{array}$ \\
\hline
\end{tabular}

The horizontal resolution is $36 \mathrm{~km}$ for all the simulations except the nested runs (2DOM and 3DOM). The lateral boundaries of the outer domain are at $30^{\circ} \mathrm{S}$ and $45^{\circ} \mathrm{N}$ for all the simulations except $1 \mathrm{DOM} \_2\left(45^{\circ} \mathrm{S}\right.$ and $\left.45^{\circ} \mathrm{N}\right)$. See Fig. 1 for domain definitions and text in Sect. 2 for further details (DOM Domain; KF Kain-Fritsch)

Table 2 The sensitivity tests using the NRCM for Case 3 during 1997

\begin{tabular}{|c|c|c|c|c|}
\hline Experiment & Integration time & Cumulus scheme & Description & Sensitivity due to \\
\hline $\mathrm{BM}$ & May-August & $\mathrm{BM}$ & $\begin{array}{l}\text { BM cumulus scheme. Warm start using } \\
\text { the restart files from } 1 \text { DOM in Table } 1\end{array}$ & BM scheme as compared to $1 \mathrm{DOM}$ in Table 1 \\
\hline NO_cumulus & May-August & No cumulus & $\begin{array}{l}\text { Same as BM, but with no cumulus } \\
\text { scheme }\end{array}$ & No cumulus scheme as compared to $1 \mathrm{DOM}$ \\
\hline 98SST & May-August & $\mathrm{KF}$ & Same as BM, but with SST from 1998 & SST as compared to $1 \mathrm{DOM}$ \\
\hline Dy_diur_SST & May-June & $\mathrm{KF}$ & High-resolution SST. Cold start & High-resolution SST \\
\hline Diur_SST & May-August & $\mathrm{KF}$ & $\begin{array}{l}\text { SST updated at every model time step. } \\
\text { Cold start }\end{array}$ & SST \\
\hline May1_KF & May-August & KF & Cold start & Initial conditions and cumulus scheme \\
\hline May1_BM & 1 May-1 June & $\mathrm{BM}$ & Cold start & Initial conditions and cumulus scheme \\
\hline Apr15_KF & 15 April-1 June & KF & $\begin{array}{l}\text { Same as May1_KF, but with different } \\
\text { initial time }\end{array}$ & Initial conditions and cumulus scheme \\
\hline Apr16_KF & 16 April-1 June & $\mathrm{KF}$ & $\begin{array}{l}\text { Same as May1_KF, but with different } \\
\text { initial time }\end{array}$ & Initial conditions \\
\hline Apr15_BM & 15 April-1 June & BM & $\begin{array}{l}\text { Same as May1_BM, but with different } \\
\text { initial times }\end{array}$ & Initial conditions and cumulus scheme \\
\hline
\end{tabular}

All simulations are 1-way nested from the reanalysis with the lateral boundaries at $30^{\circ} \mathrm{S}$ and $45^{\circ} \mathrm{N}$. The horizontal resolution is $36 \mathrm{~km}$. See text for further details (BM, Betts-Miller (Janjic 1994); KF, Kain-Fritsch (Kain 2004); Dy, Daily; Diur, Diurnal) 
Table 3 The simulations using tropical channel MM5 (TMM5) for the three cases under study

\begin{tabular}{|c|c|c|c|c|}
\hline Experiment & Integration time & Cumulus scheme & Description & Purpose \\
\hline TMM5_1 & 10 April-10 June, 2002 & $\mathrm{BM}$ & $\begin{array}{l}\text { Lateral boundaries at } \\
21^{\circ} \mathrm{S} \text { and } \mathrm{N}\end{array}$ & Case 1 simulation using TMM5 \\
\hline TMM5_2 & 10 November-31 December, 2000 & $\mathrm{BM}$ & $\begin{array}{l}\text { Lateral boundaries at } \\
21^{\circ} \mathrm{S} \text { and } \mathrm{N}\end{array}$ & Case 2 simulation using TMM5 \\
\hline TMM5_3 & 15 April-31 May, 1997 & $\mathrm{BM}$ & $\begin{array}{l}\text { Lateral boundaries at } \\
30^{\circ} \mathrm{S} \text { and } 45^{\circ} \mathrm{N}\end{array}$ & $\begin{array}{l}\text { Compare with Apr15_KF and } \\
\text { Apr15_BM in Table } 2\end{array}$ \\
\hline
\end{tabular}

The horizontal resolution is $111 \mathrm{~km}$. See text for further details [BM, Betts-Miller (Betts and Miller 1986); KF, Kain-Fritsch (Kain 2004)]

Taylor et al. 2000). The same datasets are used for TMM5 simulation for Case 3 to have similar configuration of the NRCM. Whereas, for Cases 1 and 2, the NCEP global tropospheric analyses (final or FNL; $1^{\circ} \times 1^{\circ}, 6$-h; available from 1999) are used in TMM5. A recent study comparing different reanalysis products in the context of the MJO showed very similar descriptions of the large-scale features of the MJO (available at http://climate.snu.ac.kr/ mjo_metrics/menu.htm). A merged analysis of precipitation (CMAP; $2.5^{\circ} \times 2.5^{\circ}$, daily; Xie and Arkin 1997) is also used for model validation. For brevity, both reanalysis and CMAP precipitation will be referred to as "observations".

\section{Role of the mean state}

The role of the mean state on simulated MJO statistics during 1996-2000 (1DOM in Table 1) is described first, followed by its role in individual MJO events.

(a) Obs U850

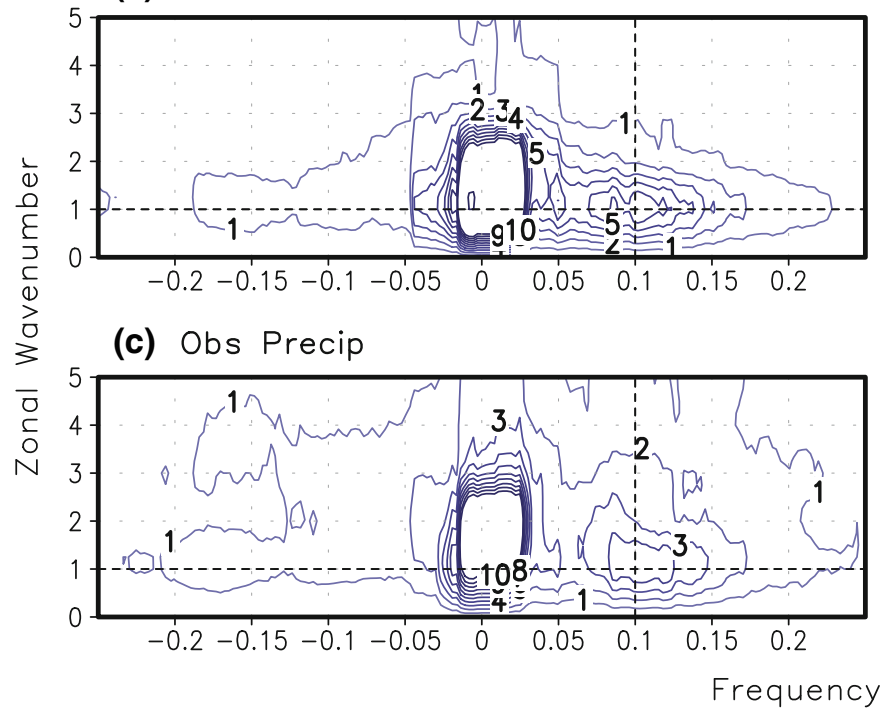

Fig. 3 Unfiltered Time-Space spectra for U850 from the a reanalysis, and b NRCM simulation 1DOM averaged over $10^{\circ} \mathrm{S}-10^{\circ} \mathrm{N}$. The bottom panels are for precipitation from the $\mathbf{c}$ observation and

\subsection{MJO statistics}

A space-time spectrum analysis (Hayashi 1979) is performed using the unfiltered time series of U850 and P to identify the intraseasonal (20-90 day) spectral peak (Fig. 3). A necessary criterion for the MJO is the dominance of the eastward propagating power over its westward propagating counterpart at the intraseasonal and planetary scales. In the observations (Fig. 3, left), the MJO spectral power is well separated from the low-frequency component and the eastward power dominates its westward counterpart at the MJO space and time scales, but not quite so in the simulation (Fig. 3, right), particularly for P (Fig. 3d). The simulated MJO signal in $\mathrm{P}$ (Fig. $3 \mathrm{~d}$ ) is much weaker than that in U850 in comparison to the observation. This discrepancy indicates a lack of physical-dynamical coherence in the simulation. The results are summarized in Table 4.

Further evidence of a lack of eastward propagation of the precipitation patterns is shown in Fig. 4. The observed precipitation clearly shows the eastward propagating phase

(b) NRCM U850

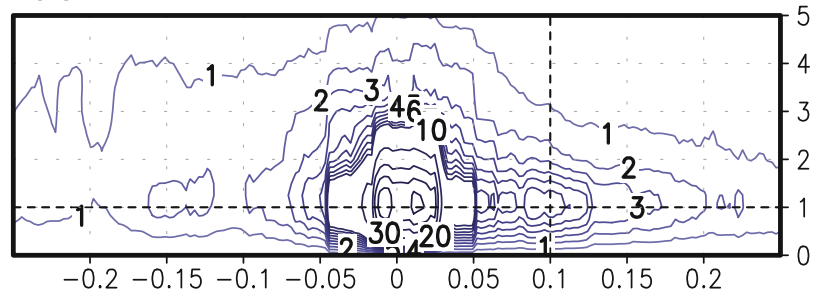

(d) NRCM Precip

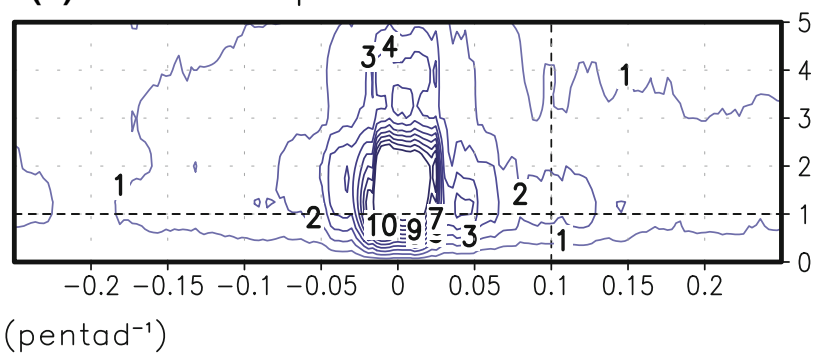

d 1DOM. Zonal wavenumber 1 and frequency 0.1 (50 days) are marked by the dashed lines 
Table 4 The ratio of eastward to westward propagating power for $850-\mathrm{hPa}$ zonal wind (U850) and precipitation (P) averaged over $10^{\circ} \mathrm{S}$ to $10^{\circ} \mathrm{N}$ at zonal wavenumbers 1 and 2 , and at 20-90 day time period

\begin{tabular}{lll}
\hline Variable & Reanalysis/CMAP & NRCM \\
\hline U850 & 2.2 & 1.8 \\
$\mathrm{P}$ & 2.1 & 1.3 \\
\hline
\end{tabular}

of the MJO, with a speed slightly more than $5 \mathrm{~m} \mathrm{~s}^{-1}$ (Fig. 4a). There is a lack of eastward propagation in the simulation (Fig. 4b) compared to the reanalysis in the Indian Ocean where the MJO was initiated. This is consistent with the precipitation spectra in Fig. 3c, d. The results are similar using other variables and different reference points.

It is natural to enquire how the MJO simulation in the NRCM compares with those in GCM simulations. A comparison of Figs. 3, 4, and Table 4 with Figs. 1, 2, and Table 3, respectively of Zhang et al. (2006) reveals that the MJO simulation in the NRCM is not better than those in GCMs. This is less than satisfactory considering that the model is forced by time-varying reanalysis boundary conditions. Further diagnoses reveal that the error in the mean state is a reason for the poor MJO statistics in the simulation.

An example of the mean state effect on the MJO variance is shown in Fig. 5. The MJO variance (contoured) and the westerlies (red hues) are reasonably collocated in the reanalysis (Fig. 5, left), but not quite as well in the NRCM (Fig. 5, right), particularly over the equatorial Indian Ocean where the initiation of the three MJO events occurred. During boreal winter (DJF), simulated westerlies and the MJO variance (Fig. 5e) are stronger and located further from the equator compared to the reanalysis (Fig. 5b, red hues). This is the season for Case 2. During boreal spring (MAM), the observed variance of the MJO is closest to the equator (Fig. 5c). The simulated variance and the westerlies during spring are shifted further from the equator, particularly in the southern Indian Ocean (Fig. 5f). Cases 1 and 3 occurred during this season. The results are similar for precipitation with overestimation in the southern hemisphere and underestimation near the equator (not shown).

\subsection{MJO cases}

In this section, we explore the ability of NRCM in capturing the three MJO events described previously. Figure 6 shows the U850 anomalies for Cases 1 and 2. The TMM5 simulations exhibit the intraseasonal switches between easterly and westerly anomalies and eastward propagation as seen in the reanalysis, especially over the Indian Ocean (Fig. 6b, e). It is quite surprising that the NRCM is able to capture these two MJO events, although with less fidelity than TMM5 (Fig. 6c, f), at about the same time as the reanalysis (Fig. 6a, d) after years from the model initial time. For Case 2, the MJO initiation region seems to shift eastward in the NRCM simulation (Fig. 6f) compared to reanalysis (Fig. 6d) and TMM5 (Fig. 6e). The MJO is thought to be unpredictable beyond 2-3 weeks (e.g., Waliser et al. 2003) in which case the reproduction of the MJO initiation by the NRCM cannot be attributed to the initial conditions. [This hypothesis will be tested in Sect. 4.4.] The implication is that a large-scale control (e.g., the effects of extratropical excitation represented by the meridional boundary conditions) is in operation.

The large-scale circulation associated with the MJO events is described in Fig. 7 in terms of U850 (colored) and U200 (contoured), respectively. The errors in the simulations are obvious, especially over the equatorial Indian and west Pacific Ocean where the maximum winds extend further north from the equator in all three cases. Moreover, the spatial scale of the easterlies is much larger in the simulation than in the observations in both the zonal and

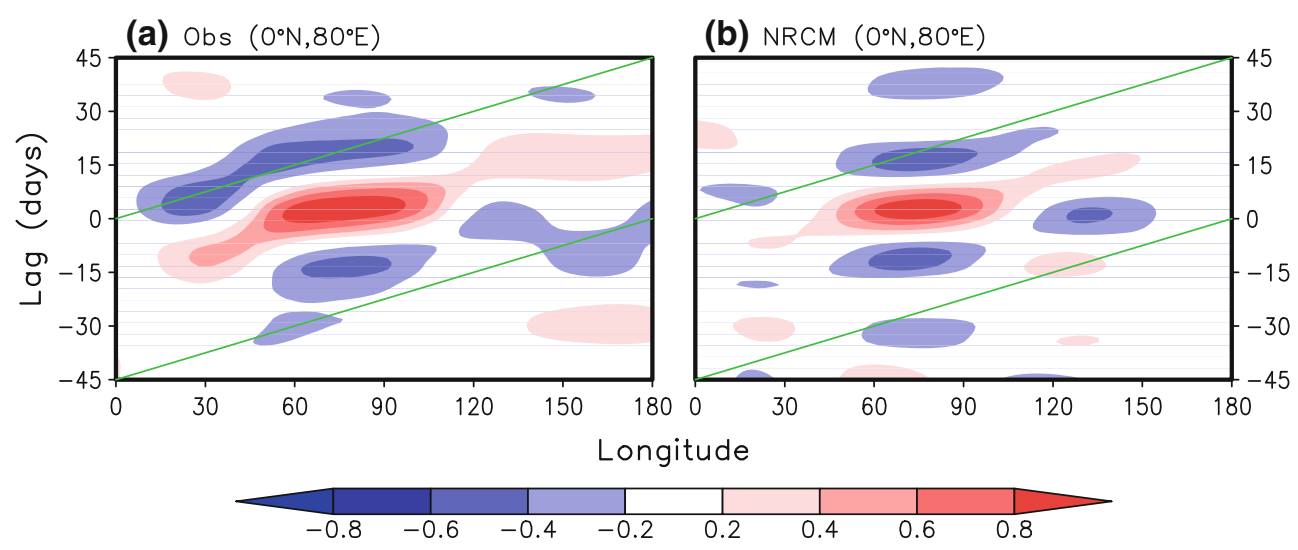

Fig. 4 Lag-correlation of the $30-70$ day precipitation averaged between $10^{\circ} \mathrm{S}$ and $10^{\circ} \mathrm{N}$, with respect to itself at $0^{\circ} \mathrm{N}$ and $80^{\circ} \mathrm{E}$ from the a observations, and $\mathbf{b}$ NRCM simulation 1DOM. The green lines mark the eastward phase speed of $5 \mathrm{~m} \mathrm{~s}^{-1}$ 
(a) Obs (All season)

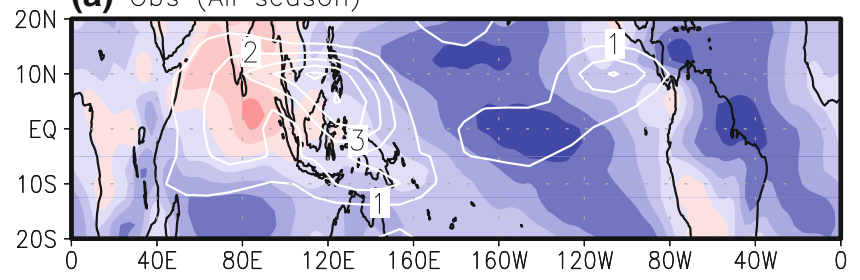

(b) Obs (DJF)

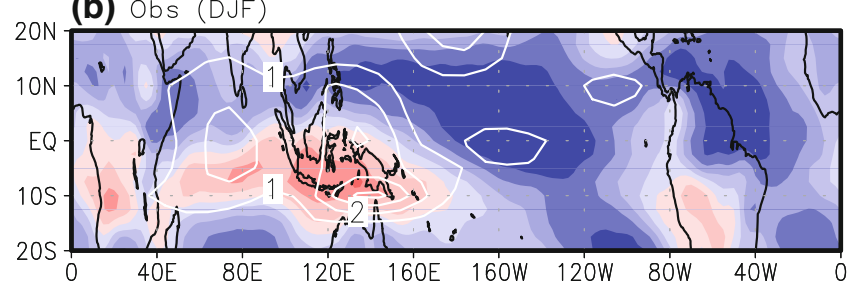

(c) Obs (MAM)

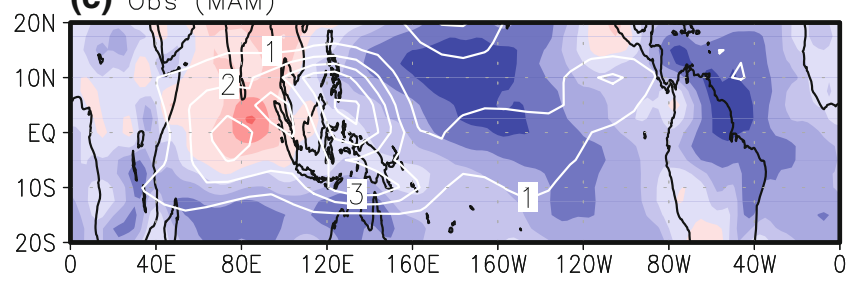

(d) $\mathrm{NRCM}$ (All season)

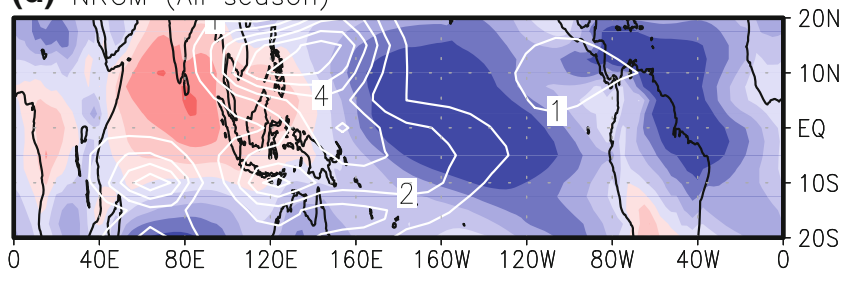

(e) NRCM (DJF)

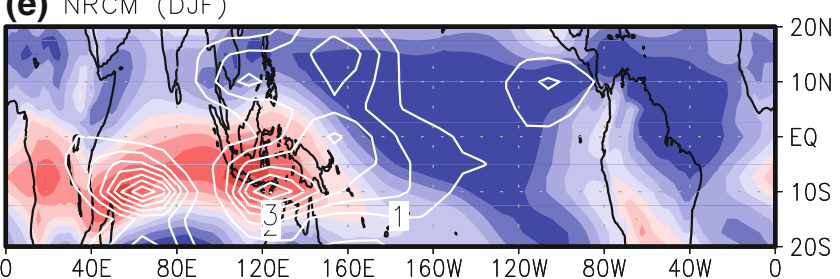

(f) $\operatorname{NRCM}$ (MAM)

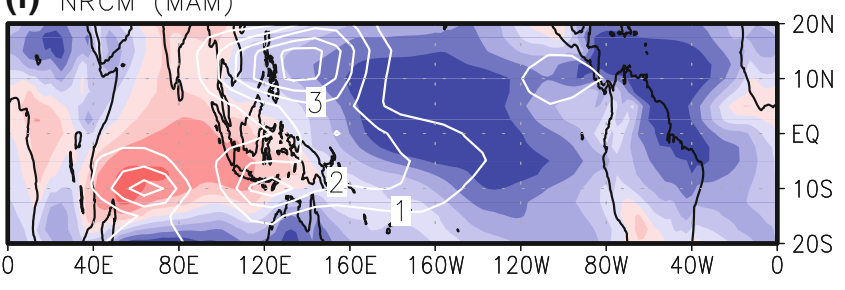

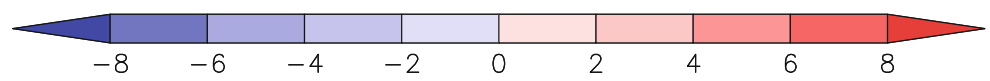

Fig. 5 Left: Mean U850 ( $\mathrm{m} \mathrm{s}^{-1}$, shaded) and MJO variance $\left(\mathrm{m}^{2} \mathrm{~s}^{-2}\right.$, contoured) during 1996-2000 from the NCEP-NCAR reanalysis considering a all seasons, b boreal winter DJF, and $\mathbf{c}$ boreal spring MAM. Right panels are from the NRCM simulation 1DOM

the meridional directions. In the zonal direction this increase in scale is partly because the amplitude of the MJO in the simulation is not decreased by the influence of the maritime continent. [Numerous observations show that the maritime continent acts as a local 'barrier' to the MJO.] In fact, the simulated winds are too strong over the maritime continent indicating that the "barrier" is less effective in the model. The systematic error in the model in Fig. 7 is consistent with that in Fig. 5. While the NRCM simulations are far from perfect, the initiations of MJO in Case 1 and Case 2 appear not to be affected by errors in the model mean state. On the other hand, the NRCM simulation 1DOM is not able to capture Case 3 over the Indian ocean (see Sects. 4, 5), and that an anomalous MJO-like westerly wind signal occurs in the western Pacific.

The errors in the mean state of the NRCM simulations are about the same in the three cases (see Sect. 4). It is possible that the lateral influences overcome the negative effects of errors in the mean state in Cases 1 and 2, but the error in the mean state dominates over the lateral influences in Case 3. However, the fidelity of the numerical simulations depend on many factors, such as resolution, cumulus parameterization, initial conditions, and SST, all of which may affect the mean state and the MJO initiation. Such aspects are examined in the next section in the context of Case 3.

\section{Sensitivity tests}

We have shown in Sect. 2.2 that the multi-year NRCM simulation successfully captures the initiation of two MJO events (Case 1 and Case 2) after years from the model initial time, but misses entirely the third event (Case 3). In order to identify the causality for the poor simulation of Case 3, we examine, through a series of numerical simulations reported in the following sections, the four hypotheses:

(1) Insufficient horizontal resolution;

(2) Deficiencies in cumulus parameterization (i.e., KF) for this event;

(3) Sensitivity to the SST distribution;

(4) Sensitivity to the initial conditions.

\subsection{Horizontal resolution}

Two simulations (2DOM and 3DOM in Table 1, see Fig. 1 for the domain definitions) are conducted to evaluate the effects of increased resolution afforded by the nested innerdomains. This is not a downscaling experiment involving increased horizontal resolution over the Indian Ocean: the objective is to explore the upscale effects on the MJO 
Fig. 6 Top: U850 anomalies $\left(\mathrm{m} \mathrm{s}^{-1}\right.$, averaged over $10^{\circ} \mathrm{S}-$ $10^{\circ} \mathrm{N}, 3$-day running mean) for Case 1 from the a NCEP-NCAR reanalysis, b TMM5 simulation TMM5_1, and $\mathbf{c}$ NRCM simulation 1DOM_2. The black straight lines indicate a zonalpropagation speed of $5 \mathrm{~m} \mathrm{~s}^{-1}$. The bottom panels are for Case 2 from the $\mathbf{d}$ reanalysis, $\mathbf{e}$ TMM5 simulation TMM5_2, and $\mathbf{f}$ NRCM simulation 1DOM

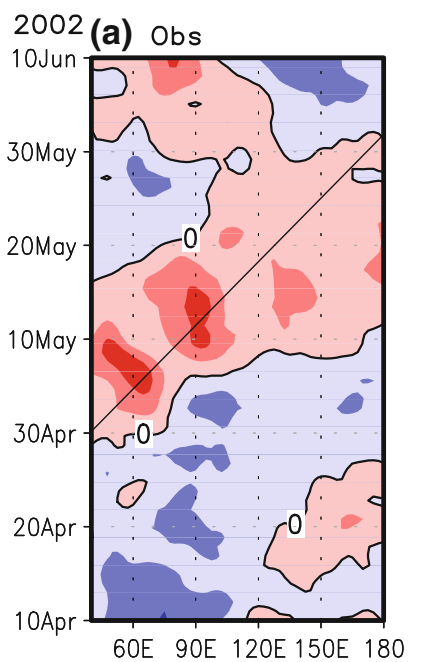

(b) TMM5_1

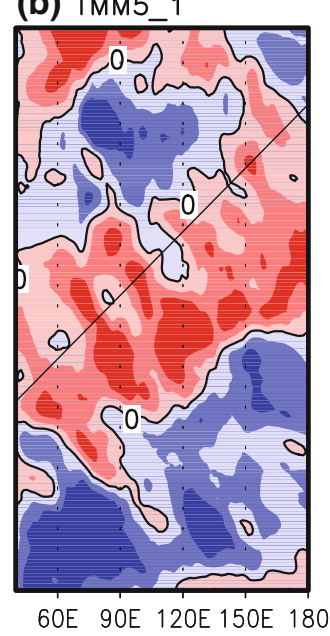

(e) TMM5_2

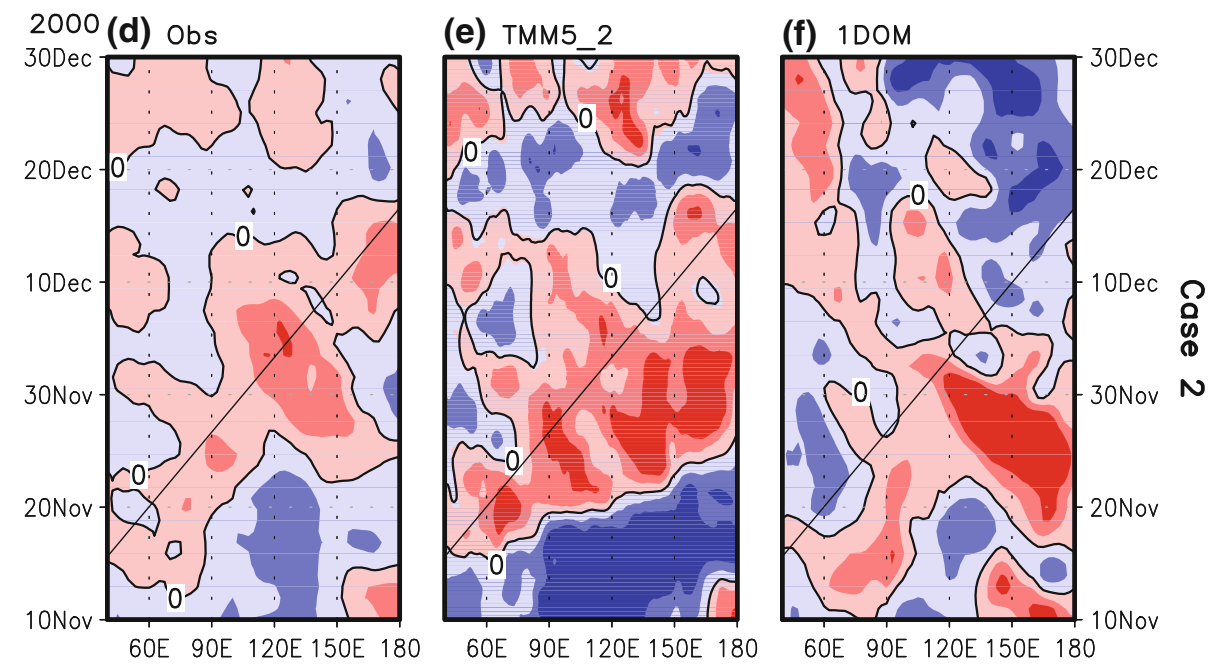

(c) $1 \mathrm{DOM} 2$

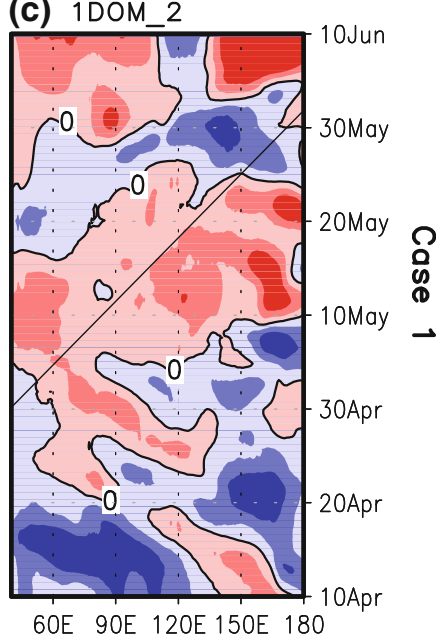

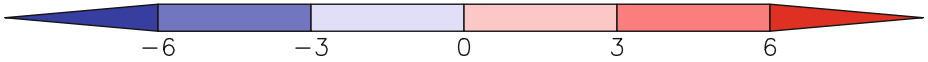

initiation of increased resolution over the Indo-Pacific warm pool region.

Figure 8 (left) shows the mean U850 (colored) and U200 (contoured) for April to June 1997. The winds are overestimated in the 1DOM simulation (Fig. 8b) compared to the reanalysis (Fig. 8a) over the equatorial regions of Indian and west Pacific Ocean. The use of 12 and $4 \mathrm{~km}$ domains (Fig. 8c, d) improves the simulation to some extent in the west Pacific Ocean. This improvement is also evident in precipitation (Fig. 8, right) over the west Pacific Ocean. The simulation statistics in terms of mean error and rmse is summarized in Table 5. The error becomes larger in the nested simulations compared to 1DOM for precipitation. The lack of precipitation over the equatorial Indian Ocean is clear in all three simulations. The cloud-system resolving simulation using the $4 \mathrm{~km}$ domain (Fig. 8h) improves the precipitation over the west Pacific, but no improvement is seen when the entire tropics is considered. The excessive and unrealistic precipitation in the southern
Indian Ocean to the east of the island of Madagascar (not shown) is produced by spurious tropical cyclones that bombard this region in each of the 1DOM, 2DOM and 3DOM simulations.

Figure 9a shows the U850 anomalies from the reanalysis during April to June 1997. The MJO propagation in Case 3 is marked by the black line, with the eastward propagating zonal wind anomalies switching from easterlies to westerlies over the Indian Ocean around May 1. Neither of the nested-domains captures this MJO event. Although there is improvement over the western Indian Ocean, there is hardly any slow eastward propagation over that region where the Case 3 initiated. Some resemblances to the reanalysis at local scales possibly occur due to the use of observed SST as the lower boundary condition of the NRCM.

All simulations (except the one with $4 \mathrm{~km}$ domain) were conducted using the KF scheme. Therefore it is natural to ponder the ability of this scheme in simulating the Case 3 . This is examined next. 
U850 (shaded) and U200 (contoured)

(a) Obs (Case 1)

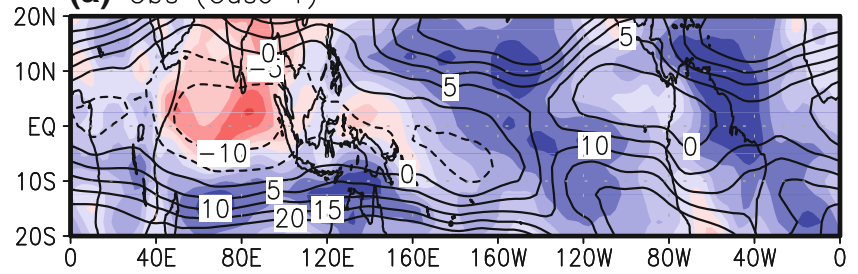

(b) Obs (Case 2)

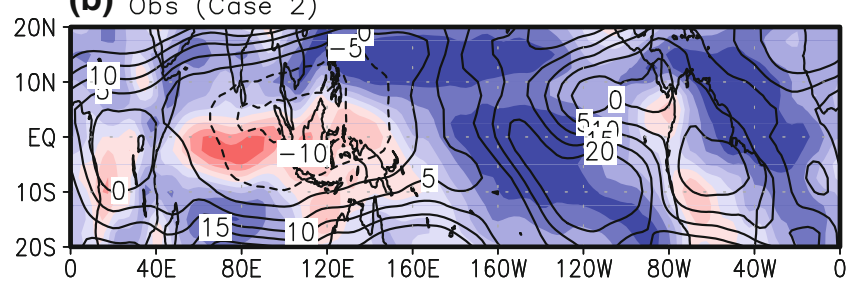

(c) Obs (Case 3)

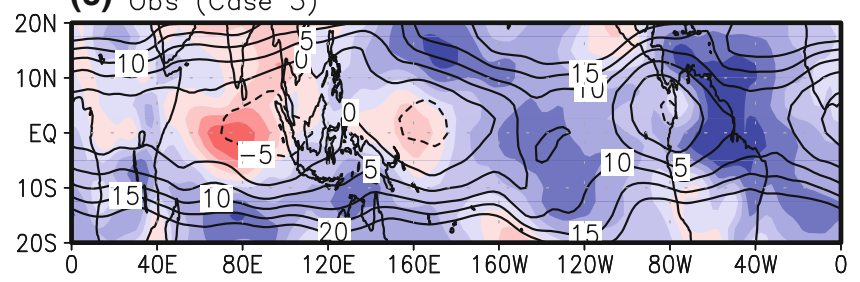

(d) NRCM (Case 1)

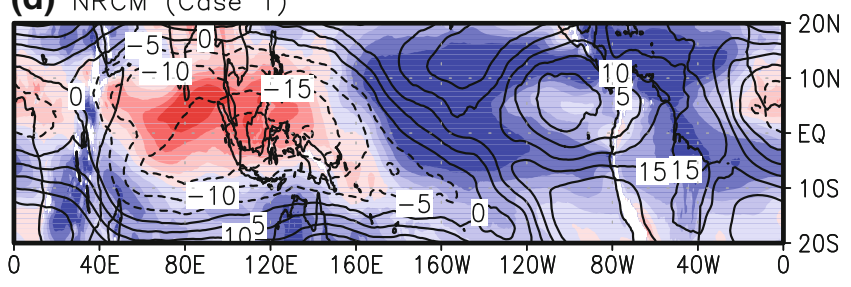

(e) $\mathrm{NRCM}$ (Case 2)

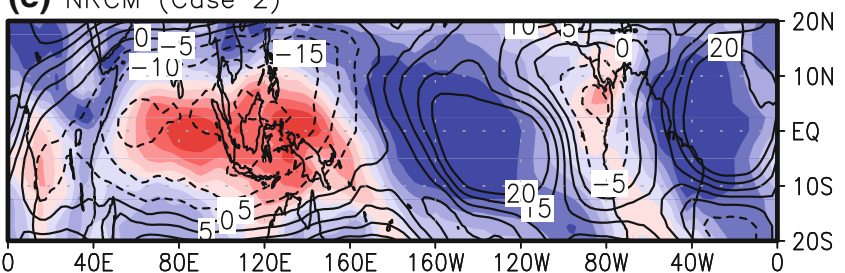

(f) $\mathrm{NRCM}$ (Case 3)

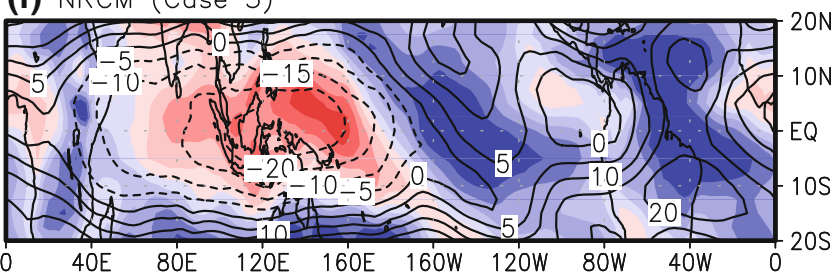

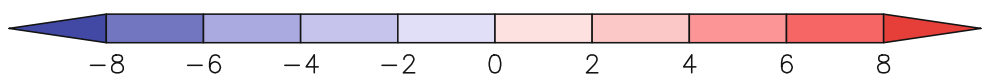

Fig. 7 Left: Mean U850 ( $\mathrm{m} \mathrm{s}^{-1}$, shaded) and U200 (contoured) from the reanalysis for a Case 1 (April 20-May 31, 2002), b Case 2 (November 1-December 10, 2000), and Case 3 (April 20-May 31,

\subsection{Cumulus parameterization}

Previous studies have shown that the fidelity of the MJO in global models is sensitive to the cumulus parameterization applied in these models (e.g., Raymond and Torres 1998; Wang and Schlesinger 1999; Maloney and Hartman 2001). However, there appears to be no satisfactory consensus. Slingo et al. (1996) found that models using convective closures based on buoyancy tend to produce better intraseasonal oscillations than those on moisture convergence, whereas a more recent study by Lin et al. (2006) found that models that produced the more satisfactory MJOs had convective closures based on moisture convergence. In general, there is a significant degree of model dependence. It is hard to know in advance which type of convective parameterization is appropriate for a particular situation.

Gustafson and Weare (2004a,b), R09, and Monier et al. (2009) made successful MJO simulation in MM5 that used Betts-Miller (Betts and Miller 1986) cumulus parameterization. Encouraged by this result, we perform two sets of TCM simulations. The first set applies the 'warm start' procedure, where the initial conditions are provided from restart files of the 1DOM simulation. Two simulations are
1997). Right panels are from the simulation 1DOM_2 for Case 1, and $1 \mathrm{DOM}$ for Cases 2 and 3. The solid (dashed) contours show positive (negative) values. The contour interval is $5 \mathrm{~m} \mathrm{~s}^{-1}$

performed, one uses the Betts-Miller-Janjic (BM in Table 2) and the other has no cumulus scheme (NO_cumulus in Table 2), therefore the convection is explicitly represented at $36-\mathrm{km}$ grid-spacing. Neither simulation produces an MJO (not shown).

The second set of three simulations uses the 'cold start' procedure where the initial and the boundary conditions are supplied by the reanalysis at May 1, 1997. The three simulations use: (1) the KF scheme (May1_KF in Table 2); (2) the BM scheme (May1_BM in Table 2); (3) the KF scheme with the diurnal cycle of SST added (Diur_SST in Table 2). All three cold-start simulations produce an MJOlike system (Fig. 10). In the reanalysis (Fig. 10a) during May, the eastward propagation of the MJO is evident. All the simulations starting from May 1 capture this propagation, albeit with errors, particularly for the BM scheme (Fig. 10d) where westward propagating synoptic-scale features are prominent and the eastward propagating system is weak. In general, irrespective of the cumulus parameterization, an MJO is simulated when the integration starts very close to or soon after the MJO initiation. Also, the KF scheme does reproduce the MJO and the associated Rossby gyres (not shown). 

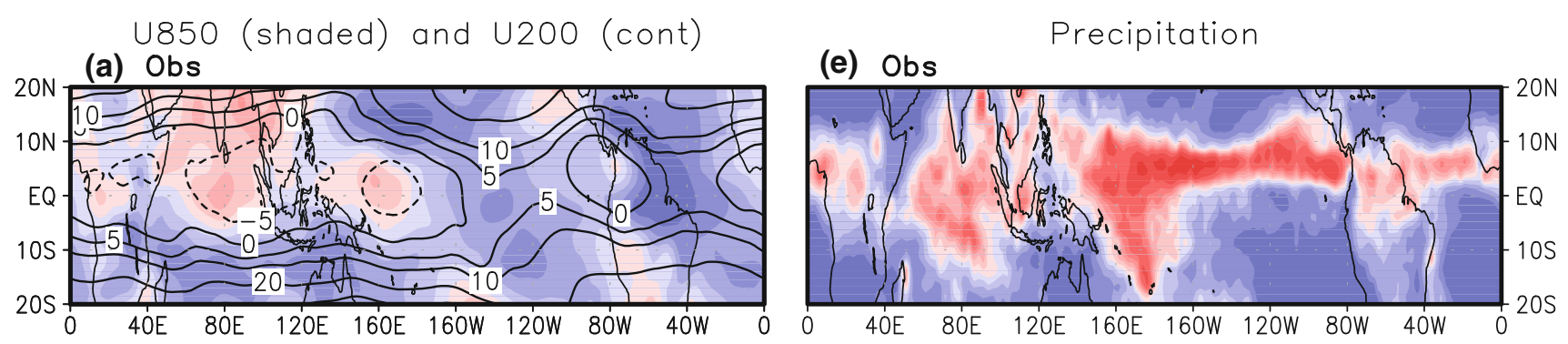

(b) $1 \mathrm{DOM}$

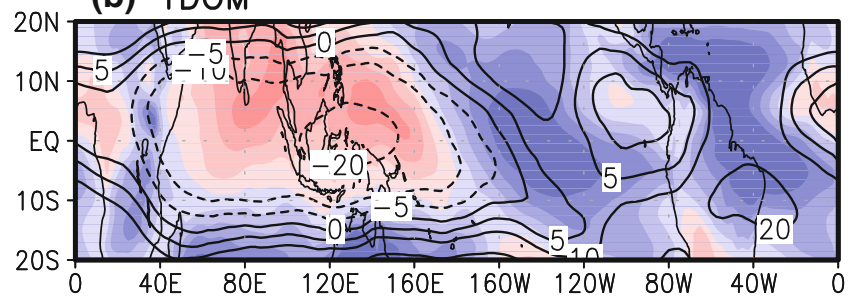

(c) $\mathrm{D} 1$ of $2 \mathrm{DOM}$

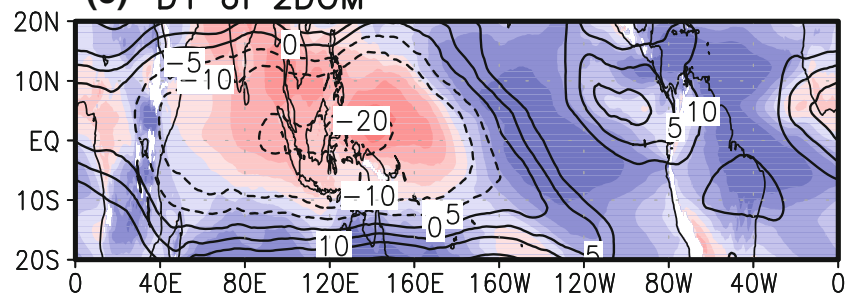

(d) $\mathrm{D} 1$ of $3 \mathrm{DOM}$
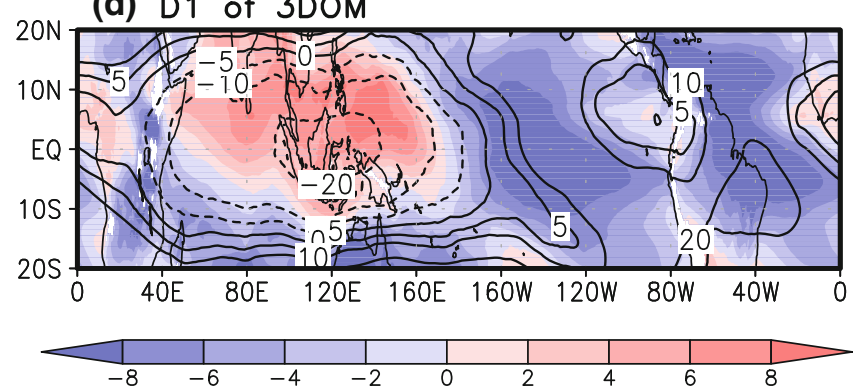

Fig. 8 Left: Mean U850 ( $\mathrm{m} \mathrm{s}^{-1}$, shaded) and U200 (m s${ }^{-1}$, contoured) for Case 3 during April-June 1997 from the a reanalysis, b D1 of 1DOM, $\mathbf{c}$ D1 of 2DOM, and d D1 of 3DOM. Right panels are for

In order to further investigate the effects of the KF and $\mathrm{BM}$ convective parameterizations, we perform three more simulations (Apr15_KF, Apr16_KF, and Apr15_BM in Table 2), starting 2 weeks before the MJO initiation in the Indian Ocean. While the model initial time is within the MJO predictability limit of 2-3 weeks, none of the simulations capture the MJO (not shown).

\subsection{Sea surface temperature}

The extent to which the simulation of Case 3 is sensitive to the SST is examined by conducting three test simulations. In the first test, SST during 1997 is replaced by SST during

\section{(f) $1 \mathrm{DOM}$}

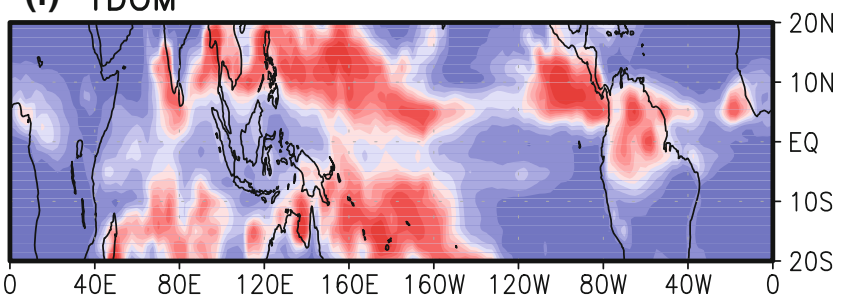

(g) $\mathrm{D} 1$ of $2 \mathrm{DOM}$

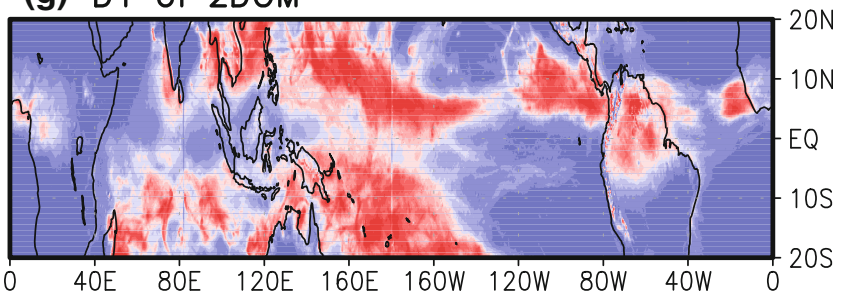

(h) D1 of 3DOM
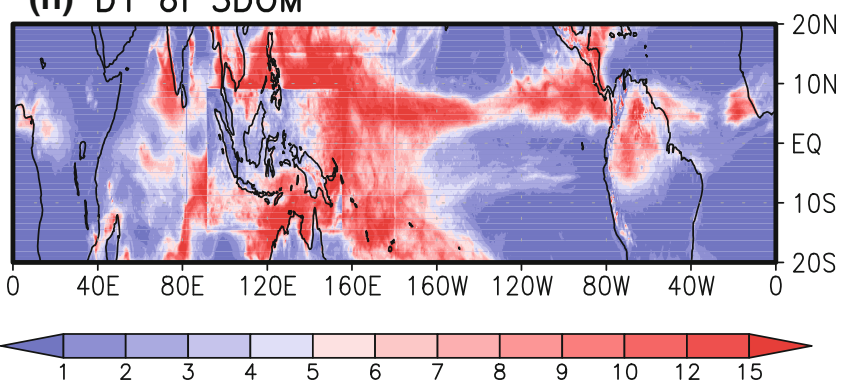

precipitation $\left(\mathrm{mm} \mathrm{day}^{-1}\right)$. The contour intervals are 5 between 0 and 10, and 10 afterwards. The solid (dashed) contours show positive (negative) values

1998 (98SST in Table 2). This is done with the expectation that the model may not properly respond to the anomalous SST pattern that occurred during 1997 (e.g., McPhaden 1999), since the MJO signal generated within a model does not necessarily reflect the SST distribution (e.g., Zheng et al. 2004). When initialized using the restart files from 1DOM, the model does not reproduce the MJO (not shown). In the second test, higher temporal and spatial resolution SST is used and the model is integrated for 2 months (Dy_diur_SST in Table 2). The results closely resemble May1_KF (Fig. 10b). In the third test, diurnal cycle of SST is added using a simple skin temperature scheme (Diur_SST in Table 2; Zeng and Beljaars 2005). 
Table 5 The errors of the simulations using different horizontal resolutions over the entire tropics $\left(20^{\circ} \mathrm{S}-20^{\circ} \mathrm{N}\right)$, and the Indian Ocean $\left(\mathrm{IO}, 20^{\circ} \mathrm{S}-20^{\circ} \mathrm{N}, 40^{\circ}-100^{\circ} \mathrm{E}\right)$ during April to June 1997

\begin{tabular}{|c|c|c|c|c|c|c|c|}
\hline \multirow[t]{2}{*}{ Variable } & \multirow[t]{2}{*}{ Region } & \multicolumn{3}{|c|}{ Mean error } & \multicolumn{3}{|l|}{ RMSE } \\
\hline & & $1 \mathrm{DOM}$ & $2 \mathrm{DOM}$ & $3 \mathrm{DOM}$ & $1 \mathrm{DOM}$ & $2 \mathrm{DOM}$ & $3 \mathrm{DOM}$ \\
\hline \multirow[t]{2}{*}{ U850 } & Tropics & 0.53 & 0.43 & 0.36 & 2.03 & 2.13 & 2.34 \\
\hline & IO & 1.61 & 1.18 & 1.20 & 2.02 & 1.72 & 1.56 \\
\hline \multirow[t]{2}{*}{ U200 } & Tropics & -4.37 & -4.07 & -2.65 & 7.02 & 7.64 & 6.98 \\
\hline & IO & -9.96 & -9.57 & -9.02 & 9.96 & 9.57 & 9.02 \\
\hline \multirow[t]{2}{*}{ P } & Tropics & 0.62 & -2.4 & -2.36 & 2.03 & 2.46 & 2.46 \\
\hline & IO & 0.83 & -2.5 & -2.52 & 2.10 & 2.54 & 2.53 \\
\hline
\end{tabular}

See Fig. 1 for domain definitions, and Table 1 for experimental details. The units are $\mathrm{m} \mathrm{s}^{-1}$ for U850 and U200, and $\mathrm{mm} \mathrm{day}^{-1}$ for precipitation

The simulated MJO in this test (Fig. 10c) is similar to that of May1_KF (Fig. 10b). In particular, both simulations produce much weaker anomalies over the western Indian Ocean, and the MJO initiation seems to be shifted eastward compared to that in the reanalysis (Fig. 10a).

The results show that higher-resolution SST does not improve the simulation of Case 3, particularly over the western Indian Ocean where the MJO initiation occurred. This is consistent with Pegion and Kirtman (2008a, b) who found that climatological SST was adequate to reproduce realistic MJO simulation over the Indian Ocean. [A representation of the oceanic mixed layer along with increased vertical resolution providing an improved diurnal cycle may more successfully simulate an MJO, (Woolnough et al. 2007).] In a coupled model, the SST feedback on the simulated MJO depends critically on the model's ability to reproduce correct mean state and basic MJO characteristics (e.g., Waliser et al. 1999; Hendon 2000). While the mean-state differences between the simulations are small, it is not known how sensitive the MJO response is to errors in the mean state. See Sect. 5 for further discussions on this.

\subsection{Initial conditions}

It appears from Sect. 4.3 that initial conditions played a role in the MJO simulation for Case 3. This is investigated in a series of test runs. Both cumulus schemes (KF and BM) are used. Examples are shown in Fig. 10b, d. All the simulations starting from May 1 when the MJO is already active in the initial conditions can generate an MJO. This is consistent with Jones et al. (2000) and Agudelo et al. (2006, 2009) among others, who found that the MJO prediction skill is improved when the oscillation is present in the initial conditions. On the other hand, no simulation starting 2 weeks prior to the MJO initiation can capture the MJO; that is, within the predictability limit of the MJO (23 weeks, Waliser et al. 2003). By degrading the quality of the initial conditions, Vitart et al. (2007) found that the MJO prediction skill was substantially reduced, and further increases in the horizontal resolution of the atmospheric model made minor impact on the MJO simulation. The quality of the initial conditions provided by the reanalysis is not known for this MJO event. At any rate, the effects of the initial conditions in a TCM are limited by the accuracy of the meridional boundary conditions. (a) Obs

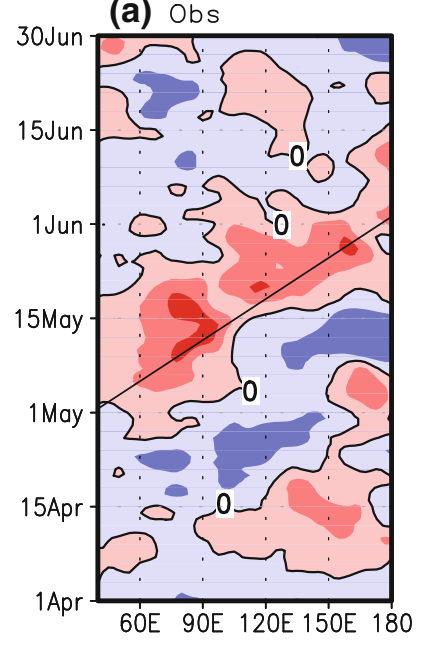

(b) $1 \mathrm{DOM}$

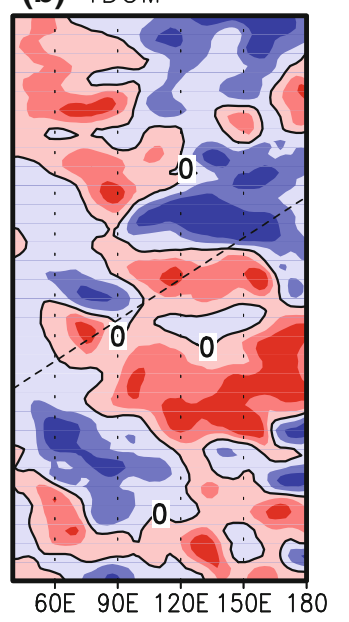

(c) $\mathrm{D} 1$ of $2 \mathrm{DOM}$

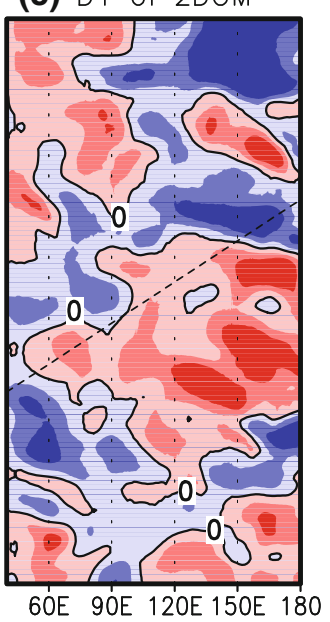

(d) $\mathrm{D} 1$ of $3 \mathrm{DOM}$

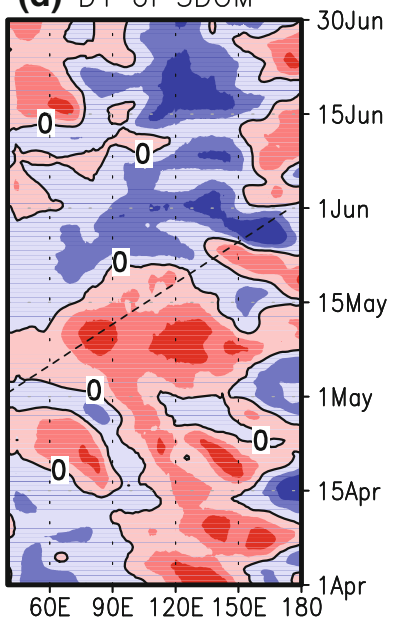

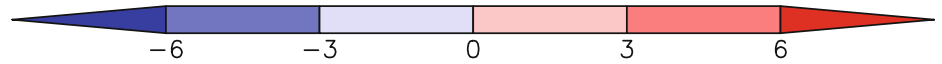

Fig. 9 Time-longitude diagrams of daily U850 anomalies ( $\mathrm{m} \mathrm{s}^{-1}$, averaged over $10^{\circ} \mathrm{S}-10^{\circ} \mathrm{N}, 3$-day running mean) for Case 3 during April-June 1997 from the a reanalysis, b 1DOM, c D1 of 2DOM, and

d D1 of 3DOM. The MJO in the reanalysis is marked by the solid line. The dashed lines in the simulations are replica of the solid line in the reanalysis 

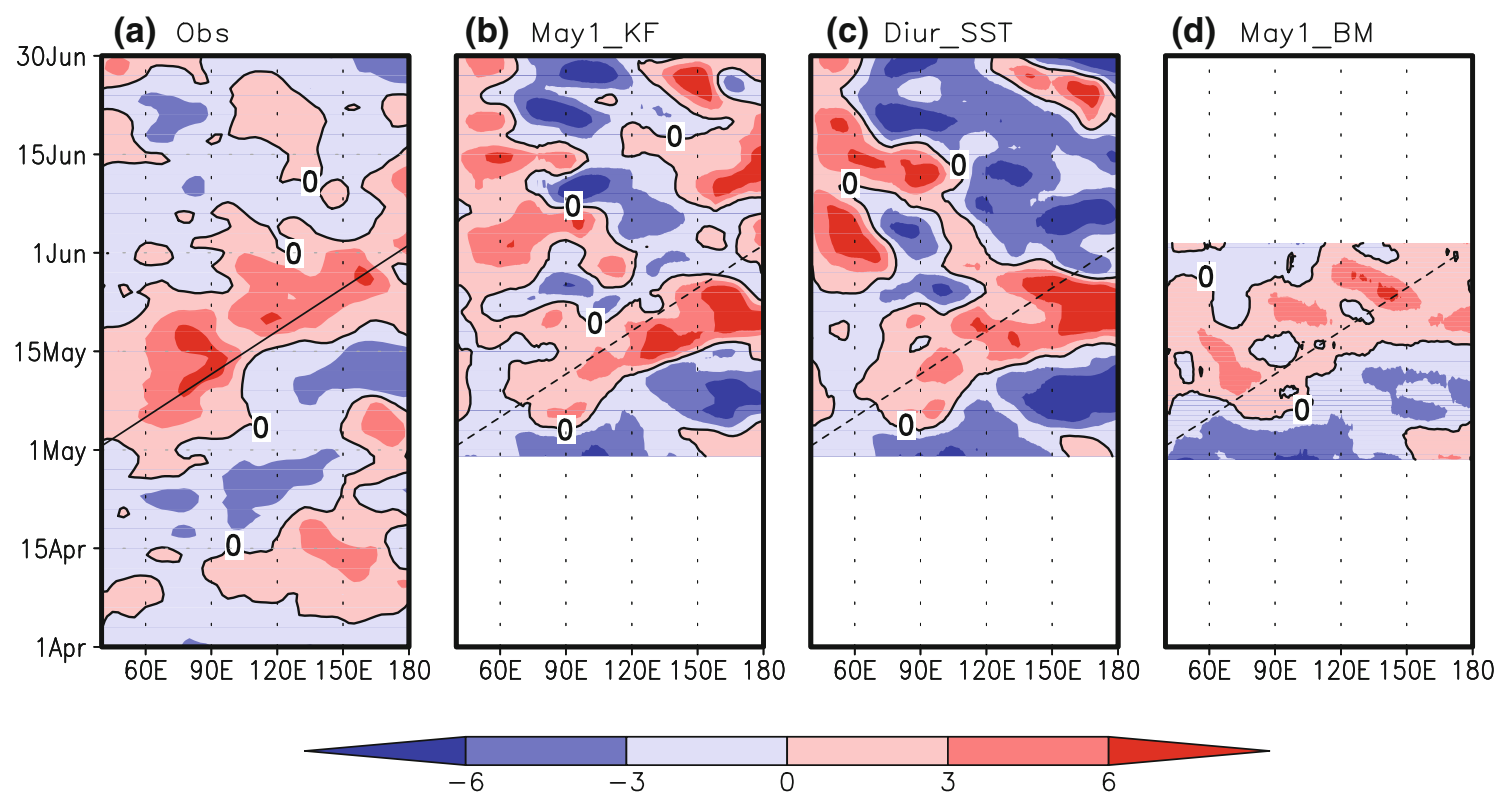

Fig. 10 Time-longitude diagrams of daily U850 anomalies $\left(\mathrm{m} \mathrm{s}^{-1}\right.$, averaged over $10^{\circ} \mathrm{S}-10^{\circ} \mathrm{N}, 3$-day running mean) for Case 3 during April-June 1997 from the a reanalysis, b May1_KF using KainFritsch scheme, c Diur_SST with the diurnal cycle of SST, and

It is conceivable that the model-suggested MJO predictability limit could be broken with the help of timevarying lateral boundary conditions, on the premise that the model would reproduce a reasonable mean state and facilitate the effects of the boundary excitation. A logical hypothesis is that the growth of model error would prevent the initiation of Case 32 weeks in advance. This hypothesis is tested in the next section.

\section{Error growth}

To explore causality in the inability to simulate Case 3, we examine the mean state and error growth from different test simulations. An example for May 1997 is shown in Fig. 11. The westerlies at the $850-\mathrm{hPa}$ in the reanalysis (Fig. 11a) are captured well by only two simulations starting from May 1 (Fig. 11c, d). The errors are obvious in the 1DOM simulation (Fig. 11b). Interestingly, mean U850 for Apr15_KF (Fig. 11e) is very similar to that of 1DOM (Fig. 11b), with anomalously lower (higher) values of U850 over the Indian Ocean (west Pacific). Such errors are not present in the cold start simulations (Fig. 11c, d). This is indicative of the error in the mean state that might have affected the MJO initiation for Case 3. The simulated U200 is too strong compared to that of the observations over the Indo-Pacific warm pool region (Fig. 11, contour). The lack of precipitation in the simulations in the near equatorial region is obvious (Fig. 11, right), which is consistent with d May1_BM using Betts-Miller scheme. All test runs started from May 1. The MJO in the reanalysis is marked by the solid line. The dashed lines in the simulations are replica of the solid lines in the reanalysis

the lack of eastward propagation of precipitation shown in Figs. 3 and 4. The performances of these simulations are summarized in Table 6.

Humidity has been suggested to be important to the MJO in observations (Kemball-Cook and Weare 2001) and numerical simulations (e.g., Agudelo et al. 2009; Maloney 2009). Its possible effects on Case 3 are shown in Fig. 12. The positive humidity anomalies associated with the MJO initiation in the lower- and mid-troposphere over the Indian Ocean in the reanalysis (Fig. 12a) are captured well by the May1_BM simulation (Fig. 12d) although with bias in magnitude. This is consistent with the results of Gustafson and Weare (2004a, b) and R09 who successfully used Betts-Miller (Betts and Miller 1986) scheme for the MJO simulation. The positive anomalies over the $80^{\circ}-100^{\circ} \mathrm{E}$ longitude were partially captured by the May1_KF simulation (Fig. 12c). However neither 1DOM (Fig. 12b) nor Apr15_KF (Fig. 12e) capture the highest positive humidity anomalies over the same region. This is related to the fact that the initiation location of positive U850 anomalies in the simulations is shifted eastward compared to the reanalysis (see Figs. 9, 10). The lower troposphere over the Indian Ocean is relatively too dry (a mean-state problem), which is consistent with the lack of precipitation (see Fig. 11, right panels). The humidity fields are similar in 1DOM (Fig. 12b) and Apr15_KF (Fig. 12e) indicating the systematic model error. Thus the failure of these simulations to capture the MJO may be related to the errors in the specific humidity (e.g., Maloney 2009). 
(a) Obs

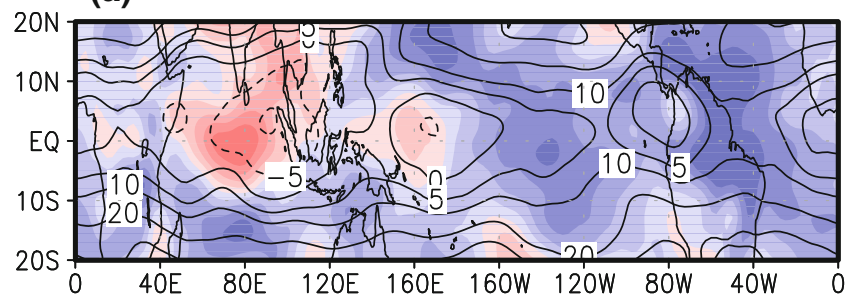

(b) $1 \mathrm{DOM}$

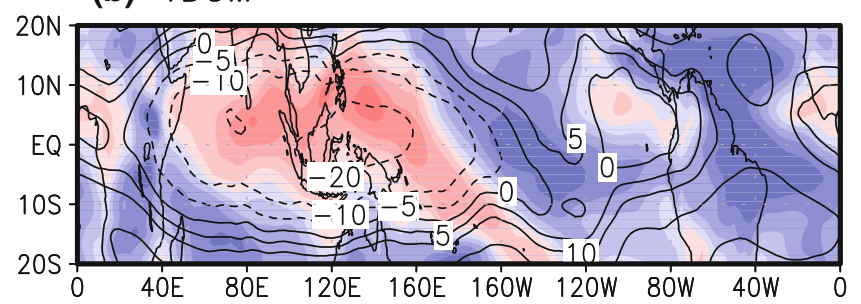

(c) May1_KF

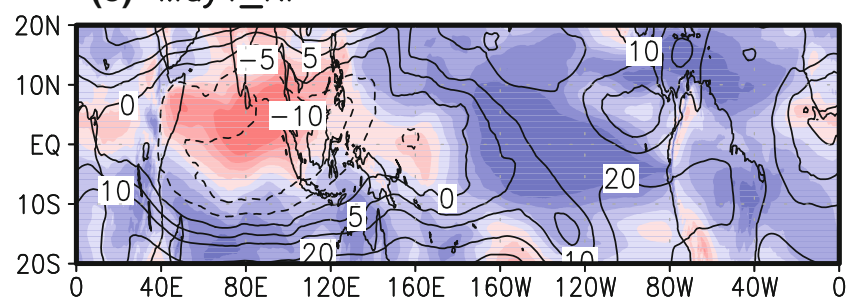

(d) May1_BM

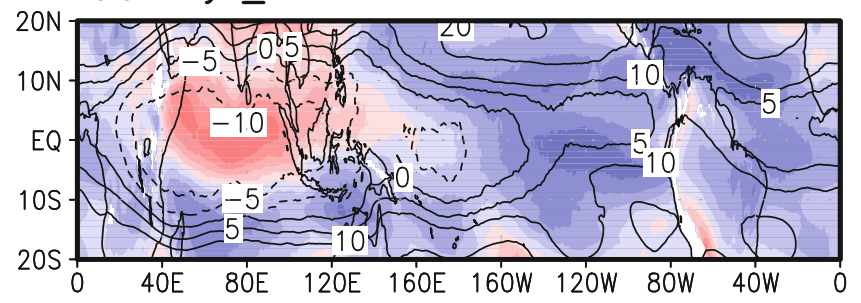

(e) Apr15_KF
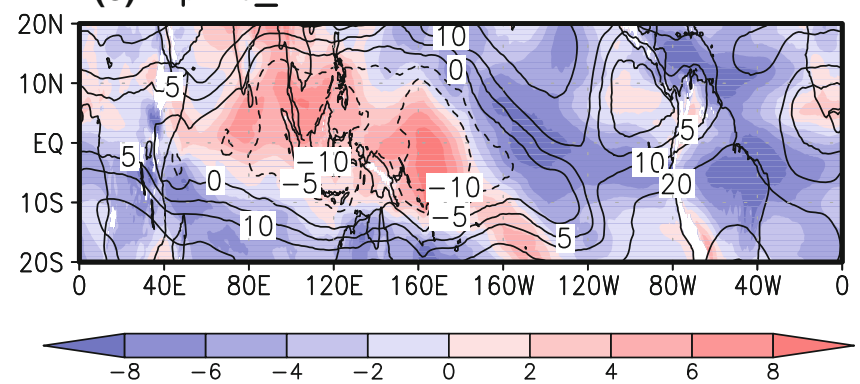

Fig. 11 Left: Mean U850 ( $\mathrm{m} \mathrm{s}^{-1}$, shaded) and U200 $\left(\mathrm{m} \mathrm{s}^{-1}\right.$, contoured) during May 1997 from the a reanalysis, b 1DOM c May1_KF (cold start from May 1 using KF scheme), d May1_BM (cold start from May 1 using BM), and e Apr15_KF (cold start from

We investigate the error growth in U850 and precipitation by estimating the evolution of rmse, calculated using pentad data at a resolution of $5^{\circ} \times 5^{\circ}$. The results are shown for only those simulations that had cold (f) Obs

\section{Precipitation}

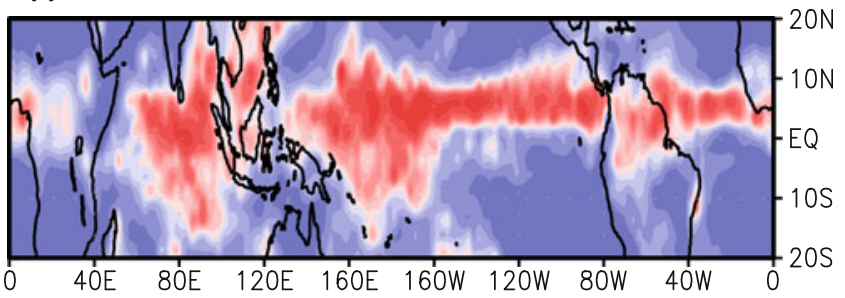

(g) $1 \mathrm{DOM}$

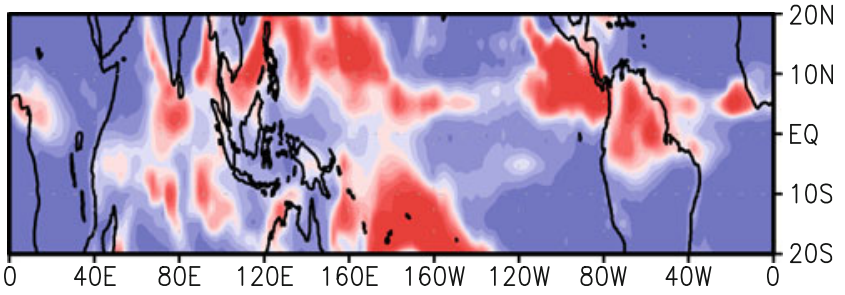

(h) May1_KF

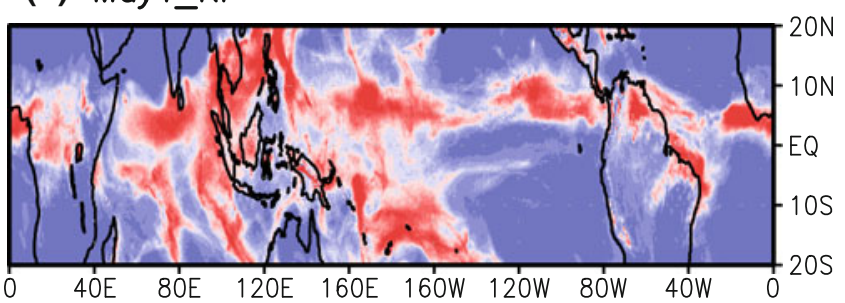

(i) May1_BM

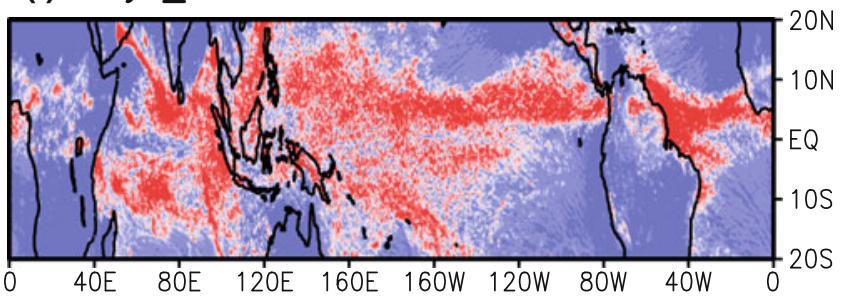

(j) Apr15_KF
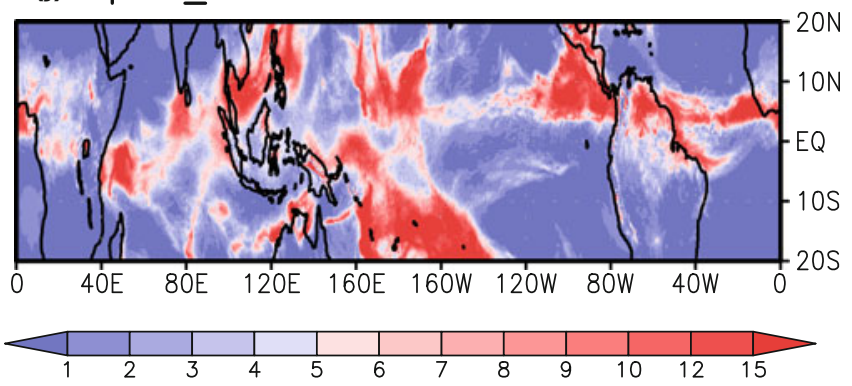

April 15 using KF). Right panels are for precipitation $\left(\mathrm{mm} \mathrm{day}^{-1}\right)$. The contour intervals are 5 between 0 and 10, and 10 afterwards. The solid (dashed) contours show positive (negative) values

initialization. Figure 13 (left) shows the evolution of rmse for U850 from the six simulations. Considering the entire domain (Fig. 13a) and as expected, the largest error around April 16 (when three simulations started) is for 1DOM. 
Table 6 The errors of the sensitivity simulations over the entire tropics $\left(20^{\circ} \mathrm{S}-20^{\circ} \mathrm{N}\right)$, and the Indian Ocean $\left(\mathrm{IO}, 20^{\circ} \mathrm{S}-20^{\circ} \mathrm{N}, 40^{\circ}-100^{\circ} \mathrm{E}\right)$ during May 1997

\begin{tabular}{|c|c|c|c|c|c|c|c|c|c|}
\hline \multirow[t]{2}{*}{ Variable } & \multirow[t]{2}{*}{ Region } & \multicolumn{4}{|c|}{ Mean error } & \multicolumn{4}{|l|}{ RMSE } \\
\hline & & $1 \mathrm{DOM}$ & May1_KF & May1_BM & Apr15_KF & $1 \mathrm{DOM}$ & May1_KF & May1_BM & Apr15_KF \\
\hline \multirow[t]{2}{*}{ U850 } & Tropics & 0.62 & 0.04 & 0.29 & 0.92 & 1.93 & 1.64 & 1.98 & 1.80 \\
\hline & IO & 0.11 & 0.79 & 1.15 & 0.26 & 1.34 & 1.76 & 1.87 & 1.33 \\
\hline \multirow[t]{2}{*}{ U200 } & Tropics & -5.74 & -1.49 & -4.2 & -2.62 & 7.7 & 5.02 & 5.5 & 5.43 \\
\hline & IO & -8.7 & -6.2 & -8.8 & -0.3 & 8.7 & 6.45 & 9.07 & 3.74 \\
\hline \multirow[t]{2}{*}{$\mathrm{P}$} & Tropics & 0.54 & 0.37 & -2.32 & -2.5 & 2.21 & 1.68 & 2.41 & 2.57 \\
\hline & IO & -0.32 & 0.49 & -2.5 & -3.06 & 1.57 & 2.00 & 2.68 & 3.07 \\
\hline
\end{tabular}

See Fig. 1 for domain definitions, and Tables 1 and 2 for experimental details. The units are $\mathrm{m} \mathrm{s}^{-1}$ for U850 and U200, and mm day ${ }^{-1}$ for precipitation

Simulations started in mid April have much less initial error compared to the 1DOM simulation at that time, but the errors drift to the "climate error" within about 15 days. Simulations starting from May 1 exhibit similar features. In the tropics $\left(10^{\circ} \mathrm{S}-10^{\circ} \mathrm{N}\right.$, Fig. $\left.13 \mathrm{~b}\right)$, the error growth shows similar pattern. Interestingly, more than $50 \%$ of the "climate error" is developed within the first 5 days of the simulation, as documented by Boyle et al. (2008) for GCMs. As expected, the error in the tropics (Fig. 13b) is larger than that in the entire domain (Fig. 13a).

Figure 13a and $b$ are repeated in Fig. 13c and d by doing an ensemble of the simulations. The May1 ensemble includes two simulations (May1_KF, and May1_BM) and the Apr16 ensemble includes three simulations (Apr15_KF, Apr16_KF, and Apr15_BM). Both ensembles show similar behavior compared to the individual simulations (Fig. 13, right). Again, the errors are larger in the equatorial region (Fig. 13d) compared to the entire domain (Fig. 13c).

Figure 14 shows the error growth for precipitation. Again, most of the errors occur within the first 1-2 weeks (Fig. 14a), but within the equatorial region, the error exceeds that of the 1DOM simulation for simulations starting from May 1 (Fig. 14b). This suggests that spinup errors are larger for precipitation than for U850. Interestingly, the model still reproduces the eastward propagation of U850 anomalies (see Fig. 10), indicating that the precipitation and winds are weakly coupled (see also Fig. 3). The rmse for precipitation is expectedly larger in the equatorial region for all simulations. Figure $14 \mathrm{c}$ and $\mathrm{d}$ show the precipitation rmse for the ensembles. The error within 5-days is comparable or larger than that of $1 \mathrm{DOM}$ simulation in the equatorial region (Fig. 14d).

The error shows similar pattern when individual ocean basins (Indian Ocean sector $40^{\circ} \mathrm{E}-100^{\circ} \mathrm{E}$, and west Pacific sector $130^{\circ} \mathrm{E}-180^{\circ}$ ) are considered (Fig. 15). An intriguing result is that the rmse between the Indian Ocean and west Pacific is out of phase, and is generally larger for the west
Pacific than the Indian Ocean. For simulations starting from May 1, the error in precipitation grows over the Indian Ocean, and reduces over the Pacific (green lines in Fig. 15c) initially. This is due to the active (Indian Ocean) and break phase (west Pacific) of the MJO in the two regions. This situation reverses in the middle of May, when the active (break) phase of the MJO is over the west Pacific (Indian Ocean). Similar features are also found for simulations starting from April 15.

We have so far described the effects of the mean state on the initiation of the MJO as a one-way influence. This assumption is somewhat appropriate for the initiation of a single MJO event, when the model is integrated days before the initiation without interfering with other MJO event. Thus, the results presented in this section from the sensitivity simulations starting in April and May can be labeled as the effects of the mean state on the MJO. But when the simulations cover multiple MJO events, the assumption of one-way influence is unlikely to be appropriate. In reality, the effects of the mean state on the MJO and vice versa are impossible to separate, especially for the entire MJO life cycle. Therefore, the effects of the mean state on the MJO statistics as described in Sect. 3.1 also include the MJO effects on the mean state.

The physical basis for the errors in model mean state and whether part of this error may come from the MJO are important considerations. Figure 16 (left) shows the vertical structure of zonal winds from the reanalysis at different stages of the MJO. About a week before the MJO initiation (Fig. 16a), lower tropospheric westerlies are weak over the western Indian Ocean, and gradually strengthen (Fig. 16b). When the MJO is active over the Indian Ocean (Fig. 16c), baroclinic structure of the zonal winds is prominent with lower (upper)-trpospheric westerlies (easterlies) to the west of convection, and lower (upper)-tropospheric easterlies (westerlies) to the east of convection. A similar feature occurs when the MJO is active over the Pacific (Fig. 16d). 


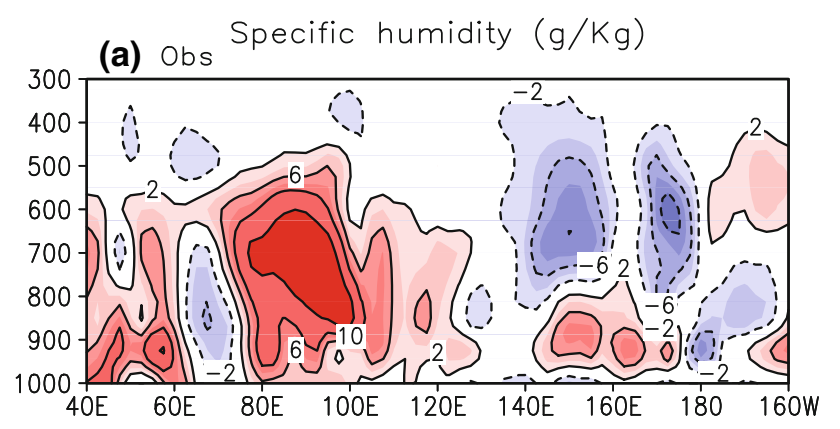

(b) $1 \mathrm{DOM}$

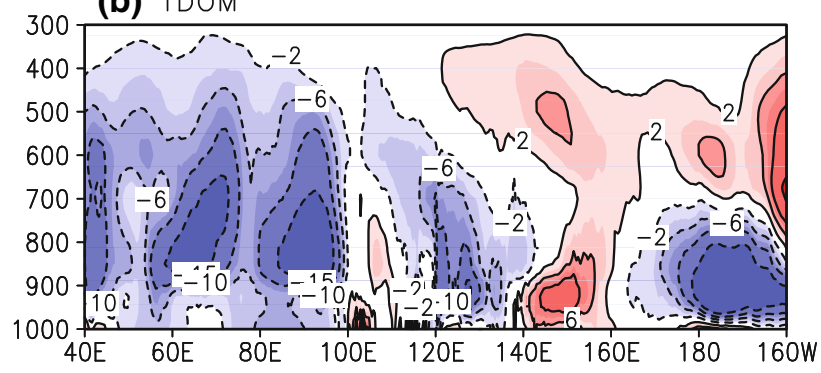

(c) May 1 KF

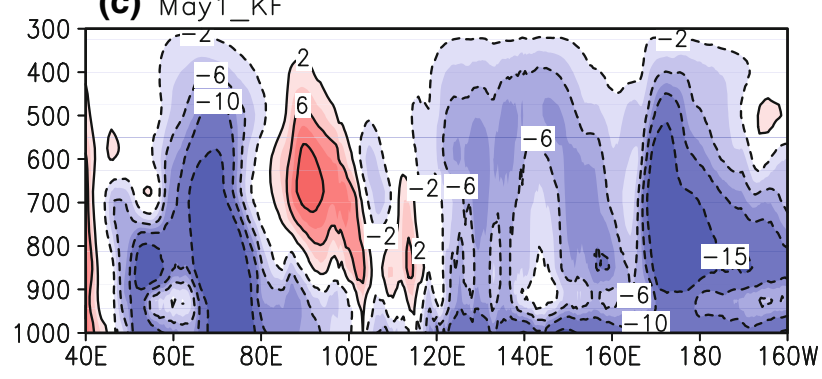

(d) May1_BM

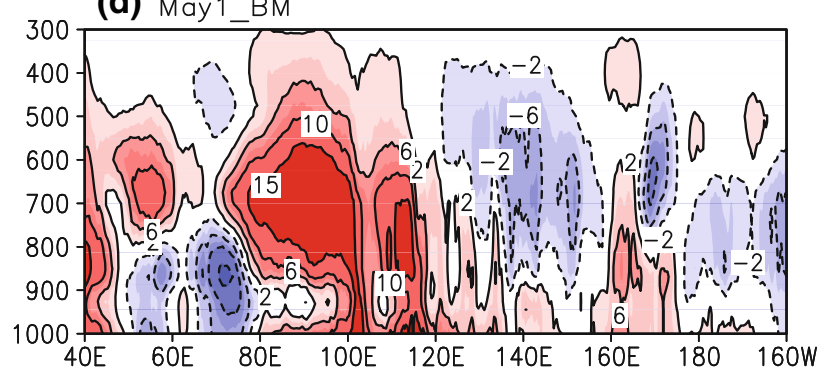

(e) Apr15_KF

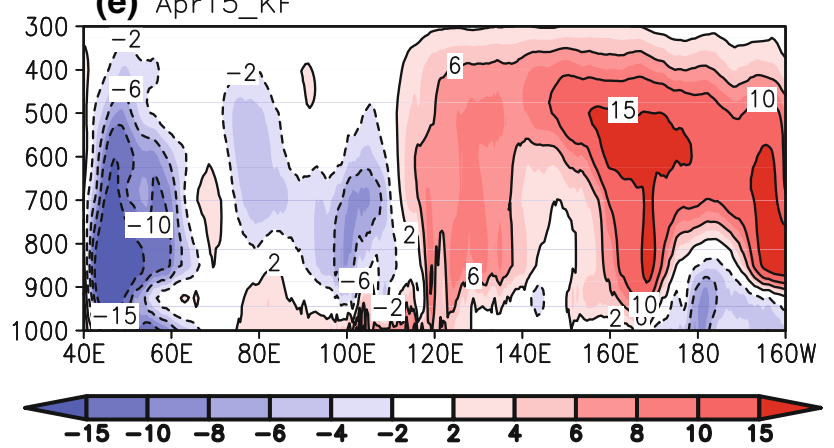

Fig. 12 The vertical structure of specific humidity anomalies $\left(10^{-1} \mathrm{~g}\right.$ $\mathrm{Kg}^{-1}$, averaged over $5^{\circ} \mathrm{S}-5^{\circ} \mathrm{N}$ ) for Case 3 during 1-5 May, 1997 from the a reanalysis, b 1DOM, c May1_KF (cold start from May 1 using KF scheme), and d Apr15_KF (cold start from April 15 using KF)
This classic picture of time evolution of the zonal winds in the reanalysis associated with the MJO is not reflected in 1DOM (Fig. 16, right). The lower-tropospheric westerlies cover a much larger longitudinal area in the model compared to the reanalysis, and are consistent with the mean U850 as shown in Figs. 5, 7, 8, and 11. Thus it is not a surprise to see an increase in the model error in the simulated U850 at the initiation of the MJO (see the green and blue lines in Fig. 13d). The vertical structure of the zonal winds in Fig. 16e and $\mathrm{f}$ resemble a quasi-stationary Walker-like circulation, which is more prominent in the nested-domain simulations (not shown) leading to error in the mean state (see Fig. 8). Are such errors in the vertical structure of zonal winds present for the two MJOs (Case 1 and Case 2) that were simulated with reasonable success?

Figure 17 shows the vertical structure of zonal winds from the reanalysis and the 1DOM simulation for the Case 2. Prior to the MJO initiation the model (Fig. 17e) realistically captures the baroclinic structure of the zonal winds present in the reanalysis (Fig. 17a). During the MJO initiation and its active phase over the Indian Ocean (Fig. 17b, c) the model overestimate the westerlies (Fig. 17f, g) that stretch further eastward. Interestingly, when the MJO is active over the Pacific (Fig. 17d), the zonal winds are very well simulated (Fig. 17h). The result shows that with direct and realistic dynamical influences from the lateral boundary conditions, it is indeed possible to capture the fundamental baroclinic structure of zonal winds within a multi-year simulation.

In general, the model errors in the individual short simulations attain the errors in the longer simulation ("climate error" in NRCM) within 1-2 weeks depending on the variables concerned. This error, in absence of direct dynamical influences from the lateral boundary conditions, prevents the MJO initiation for Case 3 in the simulations that are integrated 2 weeks before the MJO initiation over the Indian Ocean.

\section{Summary and discussion}

The three MJO events considered herein are 'successive' events according to Matthews (2008). He also found evidence of enhanced tropics-extratropics interactions prior to the initiation of such events. Two events are captured by the multi-year simulations indicating the influences from the lateral boundary conditions. The third event is not captured even when the integration is started just 2 weeks before its observed initiation. This is unexpected given that the predictability limit of the MJO is thought to be 23 weeks. To diagnose the causes behind the poor MJO simulation for this third event (Case 3), we conduct a series 


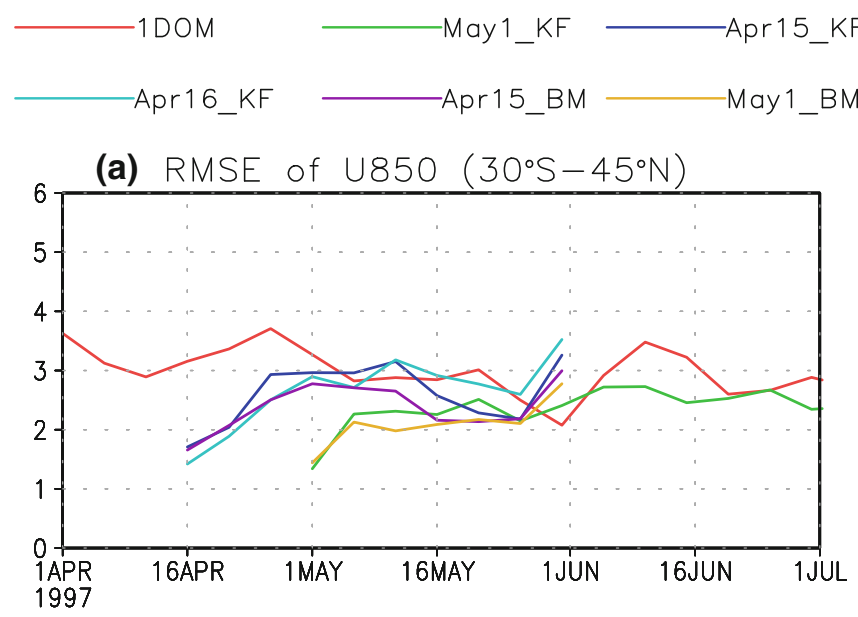

\section{$\mathrm{KF}$}

---1DOM ----May 1 -----Apr16

(c) Ensemble RMSE of U850 (30ㅇ $\left.-45^{\circ} \mathrm{N}\right)$

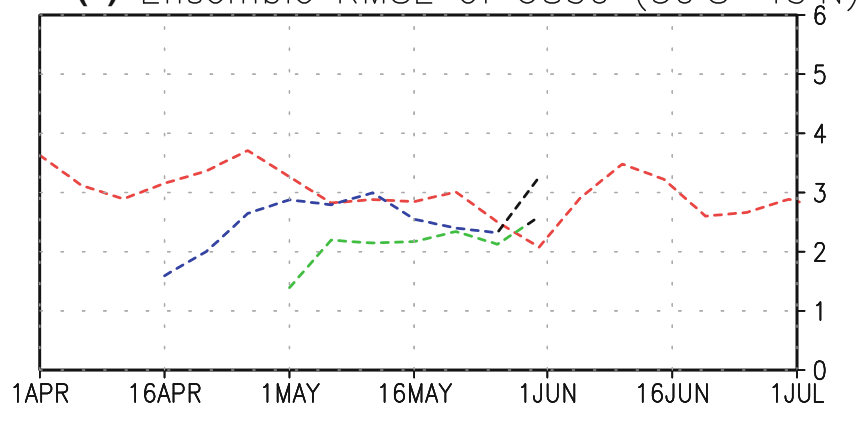

1997

(b) RMSE of U850 $\left(10^{\circ} \mathrm{S}-10^{\circ} \mathrm{N}\right)$
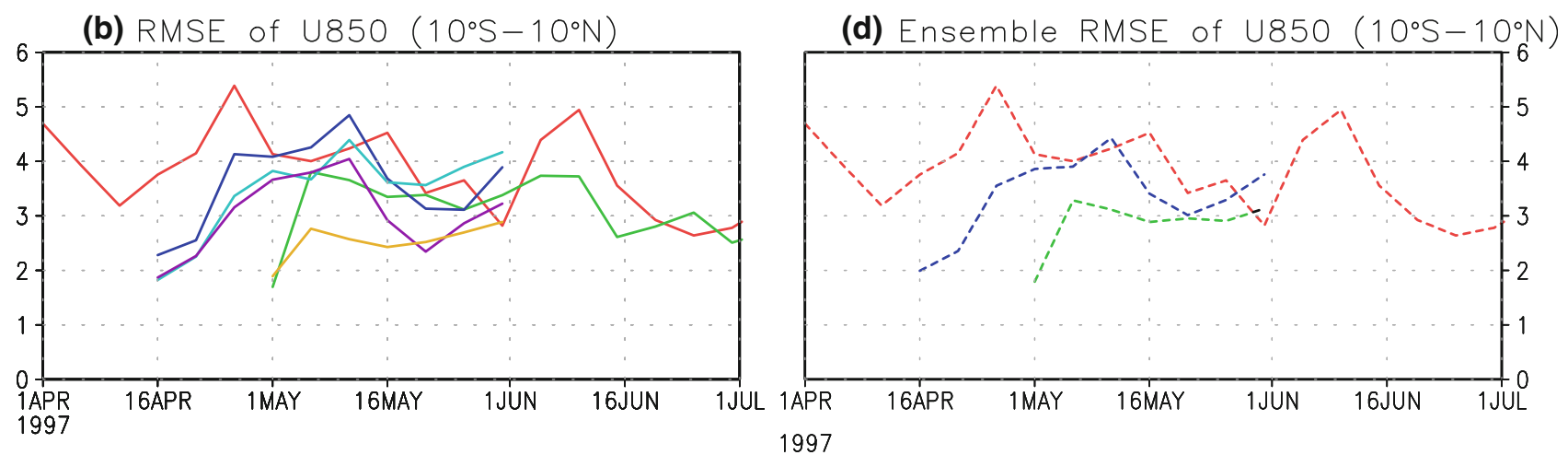

Fig. 13 Left: Root-mean-squared error (rmse) of U850 $\left(\mathrm{m} \mathrm{s}^{-1}\right)$ for simulations compared to the reanalysis over the a entire tropical channel domain $\left(30^{\circ} \mathrm{S}-45^{\circ} \mathrm{N}\right)$, and $\mathbf{b}$ equatorial region $\left(10^{\circ} \mathrm{S}-10^{\circ} \mathrm{N}\right)$. Right panels are for ensemble of simulations

of sensitivity tests. The outcomes of these tests are as follows:

(1) The nested inner-domains seem to capture convectively coupled Kelvin waves but fail to initiate the MJO; in particular, there are too many westward propagating features. The bias towards westward propagation stems from convection coupling too strongly to rotationally dominated phenomena (e.g., easterly waves and tropical cyclones are overly active), a possible cause or a consequence of the time-mean off-equatorial rain bias in the model (see Tulich et al. 2010 for details).

(2) Higher resolution over the Indo-Pacific warm pool provides little improvement as far as MJO initiation of Case 3 is concerned, but we cannot rule out possible impacts of higher resolution over much larger regions such as the entire Indian Ocean.

(3) The 5-year simulation 1DOM using KF scheme fails to simulate the Case 3 MJO event in May 1997. Three more simulations including one with BM (Janjic 1994) scheme starting from May 1, 1997 using the restart files from the $1 \mathrm{DOM}$ do not reproduce this event. Thus the BM scheme is not a remedy for the lack of MJO statistics in 1DOM especially in the presence of large errors in the initial conditions.
(4) All the cold starts for Case 3 from May 1, 1997 when the MJO is already active in the reanalysis reproduce an MJO that is comparable to the reanalysis. Evidently, both the KF and BM schemes carry the MJO signals present in the initial conditions forward in time. The KF scheme is superior to the BM scheme in regard to the MJO Case 3.

(5) The Case $3 \mathrm{MJO}$ is not captured whether the KF or the BM schemes are used when the model is integrated 2 weeks prior. This result suggests that the problems reported in (3) above are not entirely related to the large errors in the initial conditions coming from the restart files generated by long integration using the KF scheme.

(6) The TCM is an atmosphere only model forced by the SST without true oceanic feedback. Therefore, it is difficult to distinguish whether differences in the MJO simulation are due to the lack of coupled air-sea feedbacks or differences in the mean states. Such difficulties were overcome by Pegion and Kirtman (2008a) who compared MJO variability to an uncoupled simulation forced by daily SST from a coupled control run. This way they ensured that the differences between the coupled and uncoupled simulations were due to air-sea interactions. They found that airsea coupling was responsible for differences in the 


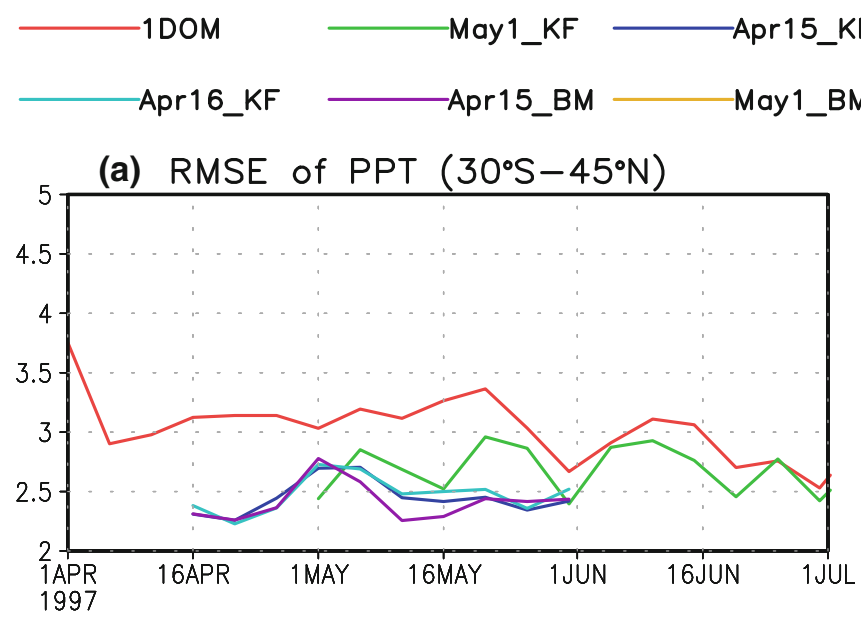

(b) RMSE of PPT $\left(10^{\circ} \mathrm{S}-10^{\circ} \mathrm{N}\right)$

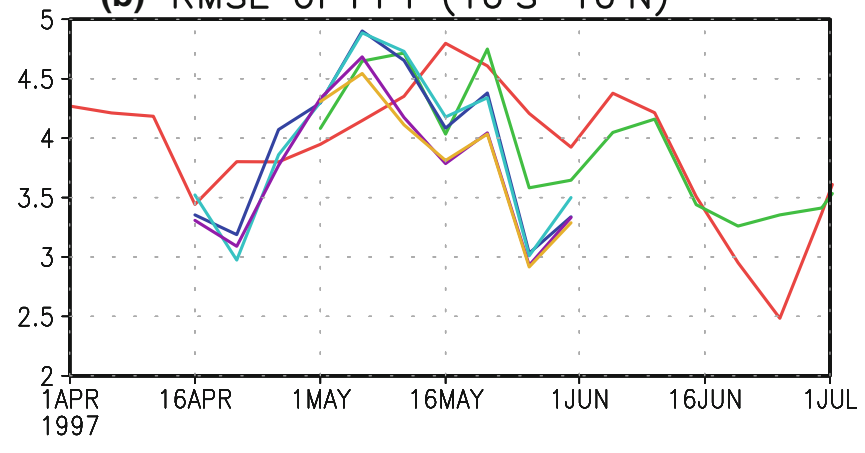

(c) Ensemble RMSE of PPT $\left(30^{\circ} \mathrm{S}-45^{\circ} \mathrm{N}\right)$

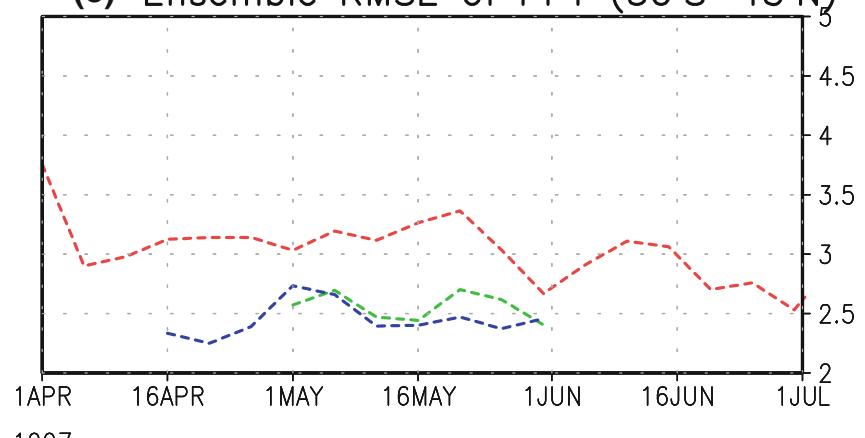

1997

(d) Ensemble RMSE of PPT $\left(10^{\circ} \mathrm{S}-10^{\circ} \mathrm{N}\right)$

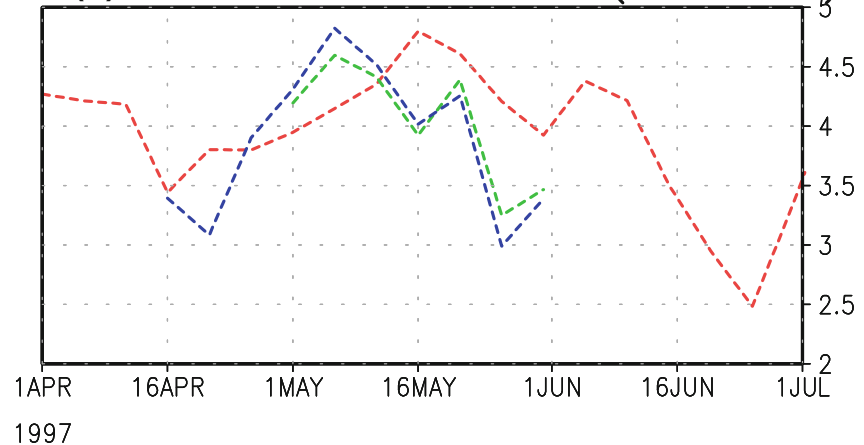

Fig. 14 Left: Root-mean-squared error (rmse) of precipitation $\left(\mathrm{mm} \mathrm{day}^{-1}\right.$ ) for simulations compared to observation over the a entire tropical channel domain $\left(30^{\circ} \mathrm{S}-45^{\circ} \mathrm{N}\right)$, and $\mathbf{b}$ equatorial region $\left(10^{\circ} \mathrm{S}-10^{\circ} \mathrm{N}\right)$. Right panels are for ensemble of simulations

simulation of the MJO between the coupled and uncoupled models, specifically in terms of organization and propagation in the western Pacific. The role of intraseasonally varying SST was found to be important to the amplitude and propagation of the oscillation beyond the Maritime continent in their model. After removing the intraseasonally varying component in the SST and lateral boundary conditions in MM5, Gustafson and Weare (2004b) found only minor differences in the MJO simulation compared to the simulation forced with observed SST. R09 also reported that use of constant SST did not influence the MJO initiation in the Indian Ocean. These results indicate that it may be possible that the MJO initiation is independent of oceanic feedback, but its amplitude and propagation is influenced by the air-sea interactions whose effect is dominant over the Pacific.

Is the TCM's inability to simulate MJO Case 3 due to shortcomings from the cumulus parameterization? The answer seems to be affirmative, because, when the TMM5 using the Betts-Miller (Betts and Miller 1986) scheme and the same lateral boundary conditions $\left(30^{\circ} \mathrm{S}\right.$ and $45^{\circ} \mathrm{N}$, TMM5_3 in Table 2) is integrated from 2 weeks before the observed MJO initiation, this event is captured (not shown). Interestingly, the lack of MJO in a channel model does not necessarily imply a lack of tropical-extratropical interaction. For example, if the observed source of perturbations that eventually initiate an MJO event is located inside the model domain, then the lateral boundary conditions may not be effective beyond the MJO predictability limit. As a result, the locations of the meridional boundaries of a TCM are crucial for capturing the extratropical influences, if any, on MJO initiation.

There are other aspects revealed by our study that require further investigation.

- The cloud-system resolving simulation (3DOM in Table 1) is subject to errors from the initial conditions, because the simulation is initialized using the restart files after 1 year from the initial time of 1DOM simulation. The initialization of the cloud-resolving domain at the beginning of the simulation also does not guarantee a better simulation in the tropics, because errors due to cumulus schemes in the mother domain certainly affect the cloud-system resolving domain in ways that are not understood. The true effects of the cloud-system resolving domain can be quantified only if all the domains are cloud-system resolving or if the 


\section{-1DOM}

(a) U850 $\left(20^{\circ} \mathrm{S}-20^{\circ} \mathrm{N}\right)$

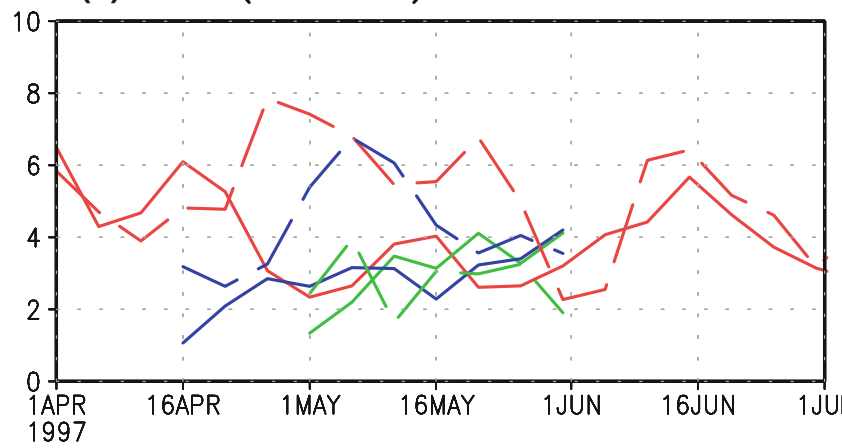

(b) U850 $\left(10^{\circ} \mathrm{S}-10^{\circ} \mathrm{N}\right)$

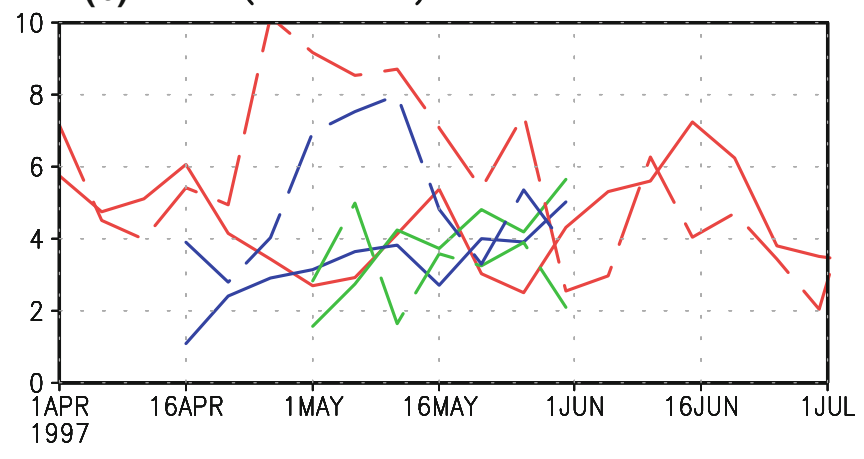

May 1 (c) PPT $\left(20^{\circ} \mathrm{S}-20^{\circ} \mathrm{N}\right)$

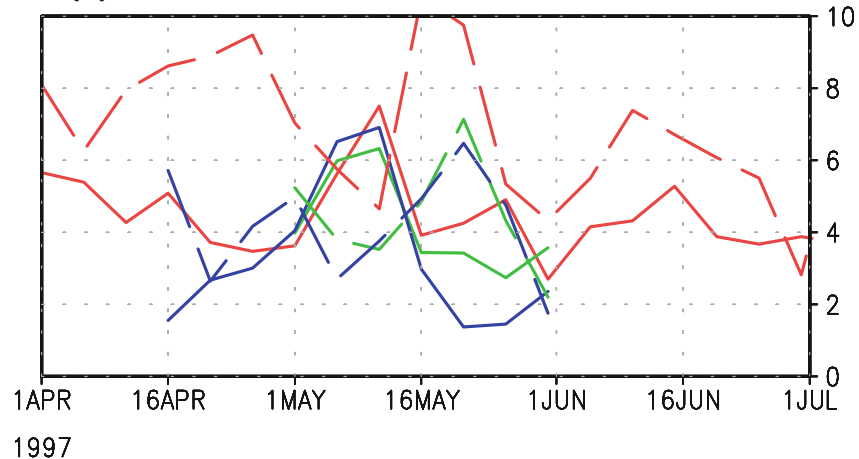

(d) PPT $\left(10^{\circ} \mathrm{S}-10^{\circ} \mathrm{N}\right)$

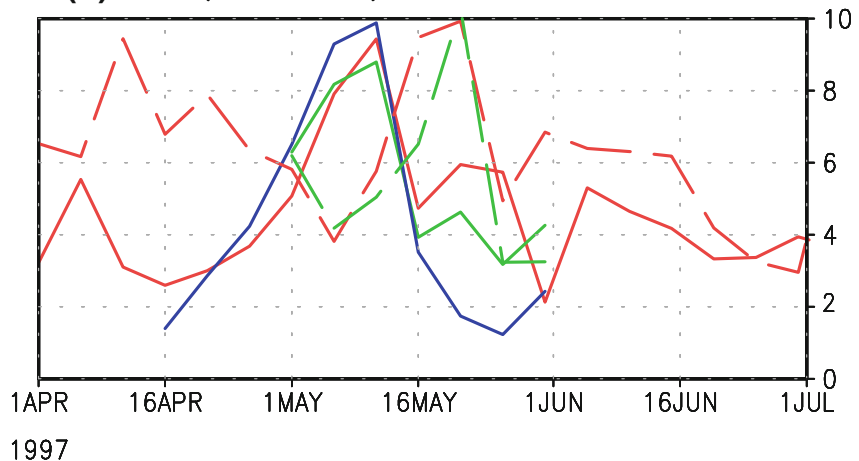

Fig. 15 Left: Root-mean-squared error of U850 $\left(\mathrm{m} \mathrm{s}^{-1}\right)$ for ensemble simulations compared to observation over the Indian Ocean $\left(40^{\circ} \mathrm{E}-100^{\circ} \mathrm{E}\right.$, solid lines) and west Pacific $\left(130^{\circ} \mathrm{E}-180^{\circ}\right.$, dotted lines). Right panels are for precipitation ( $\left.\mathrm{mm}^{-1}{ }^{-1}\right)$

cloud-system resolving domain is big enough to encompass the region of MJO initiation.

- In a regular regional model, the domain size is vital for the model climate through the influence of boundary conditions. For example, a small domain may lead to very little "climate error" because the model is fundamentally controlled by its boundary conditions. On the other hand, the climate in a global model drift would be less constrained. The tropical channel model lies between the regular regional model and the global model. Thus, climate drift in the TCM simulation would not be noticeable in the smaller regional domains used by Gustafson and Weare (2004a, b) and Monier et al. (2009). How much error in the mean state is sufficient to prevent the initiation of an MJO in the model is not known; arguably, it is event dependent. Thus a systematic study for multiple MJO events including several "primary" (no prior MJO) and "successive" (with prior MJO) events is needed to have a better idea of the effect of mean state on the MJO. Another aspect of the mean state effect on the MJO that is not described in this work is the following: Is it possible to simulate Case 3, if the TCM can reproduce reasonable mean state prior to the MJO initiation?
Unfortunately, none of the sensitivity tests reproduces a better mean state than that of 1DOM simulation prior to the MJO initiation, so this question remains unanswered.

- Problems have been reported with the new BM scheme (Janjic 1994) that was used herein for the NRCM. Using the original version of the BM scheme (Betts and Miller 1986) available within the MM5, the simulation TMM5_3 was able to capture Case 32 weeks in advance. Thus the effects of the original Betts-Miller scheme available within the MM5 package needs to be tested in the TCM framework. Such efforts are ongoing at present in collaboration between the NCAR and U. of Miami.

- The results have interesting implications for ENSO prediction. Note that the Case 3 (May 1997 MJO event) was followed shortly by a very strong ENSO event in the summer (McPhaden 1999). If Case 3 cannot be predicted beyond its believed predictability limit, then the simulated errors will undoubtedly affect the amplitude of the predicted ENSO. In fact, the precipitation associated with 1997-1998 ENSO event is disorganized in the 1DOM simulation compared to the observation, even though the model was forced by the observed SST. 
Obs

(a) $21 \mathrm{Apr} 1997$

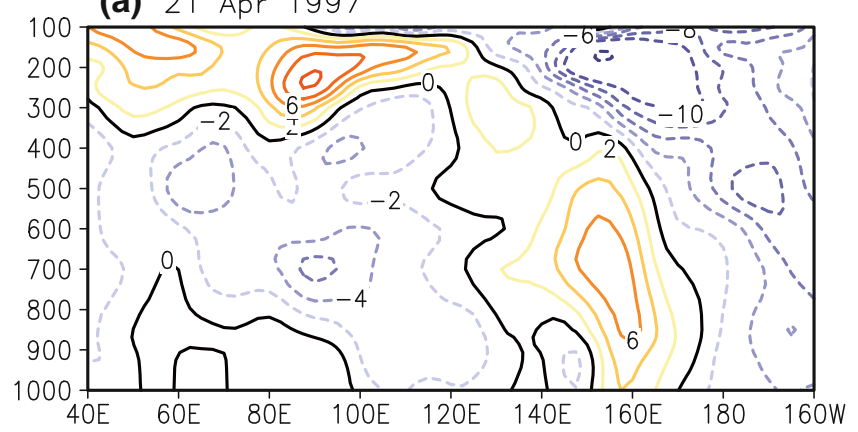

(b) $28 \mathrm{Apr} 1997$

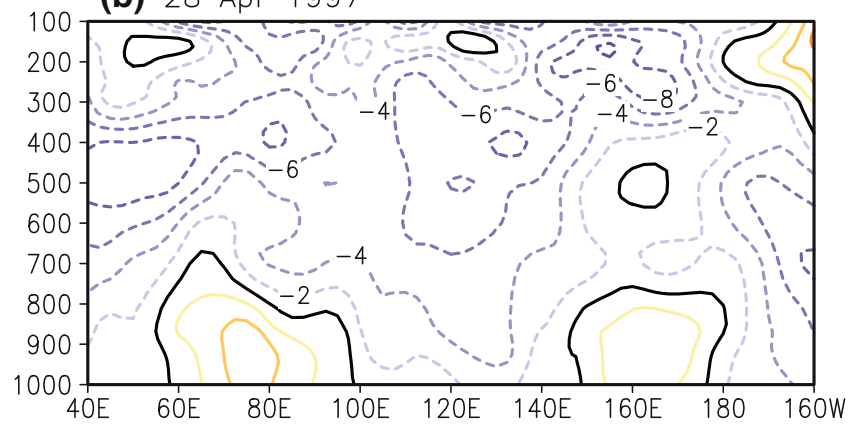

(c) 12 May 1997

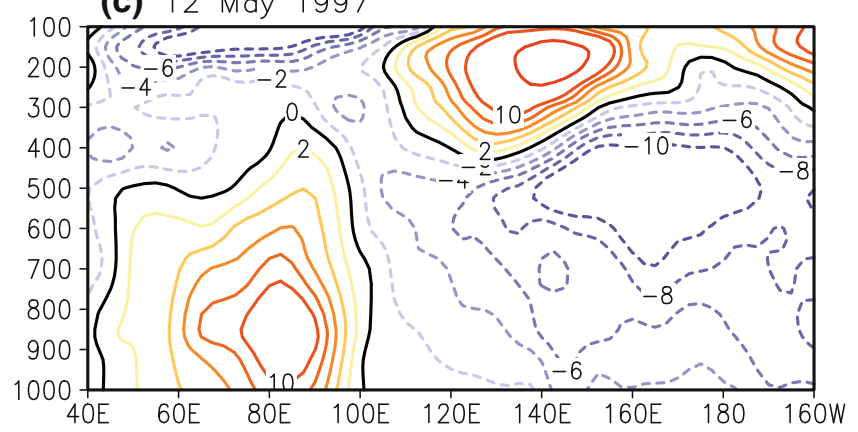

(d) 26 May 1997

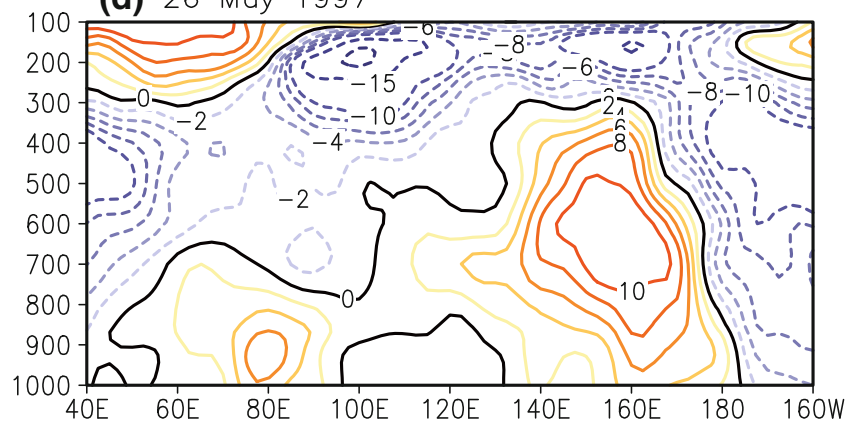

Fig. 16 Left: Vertical structure of zonal winds $\left(\mathrm{m} \mathrm{s}^{-1}\right.$, averaged over $5^{\circ} \mathrm{S}-5^{\circ} \mathrm{N}, 3$-day mean centered at the time shown above each panel) from the reanalysis for Case 3 during a April 21 (prior to the MJO initiation), b April 28 (at the MJO initiation), c May 12 (active phase of the MJO in the Indian Ocean), and d May 26 (active phase of the
$1 \mathrm{DOM}$

(e) 21 Apr 1997

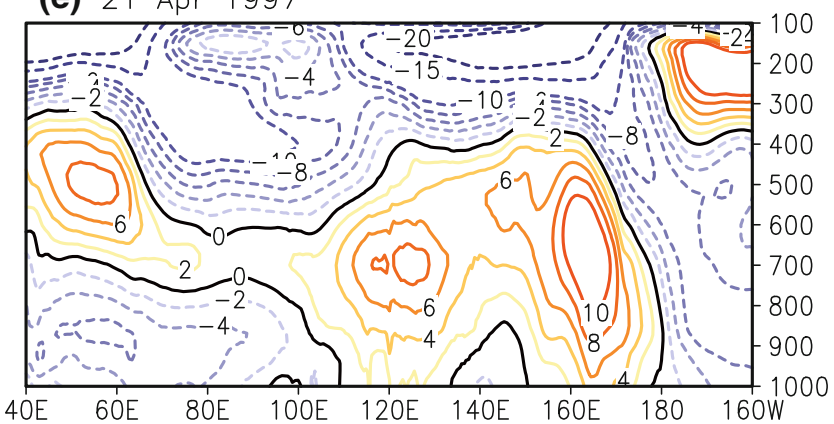

(f) 28 Apr 1997

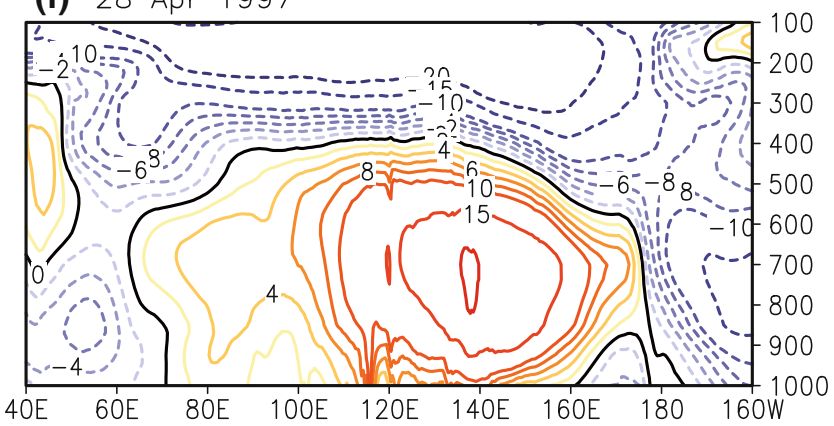

(g) 12 May 1997

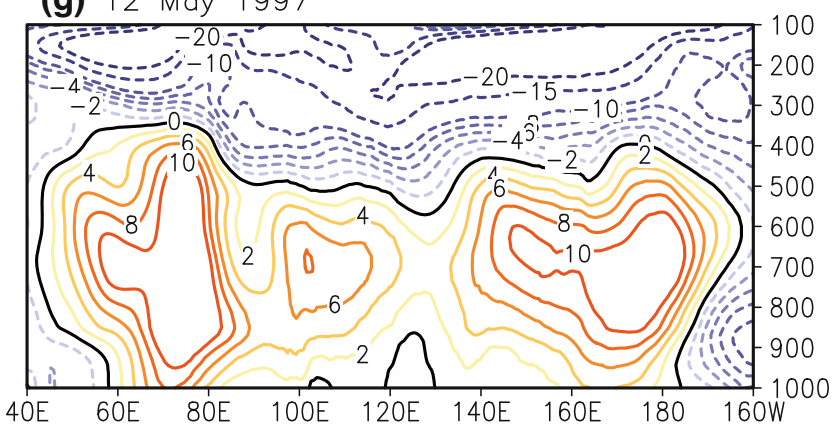

(h) 26 May 1997

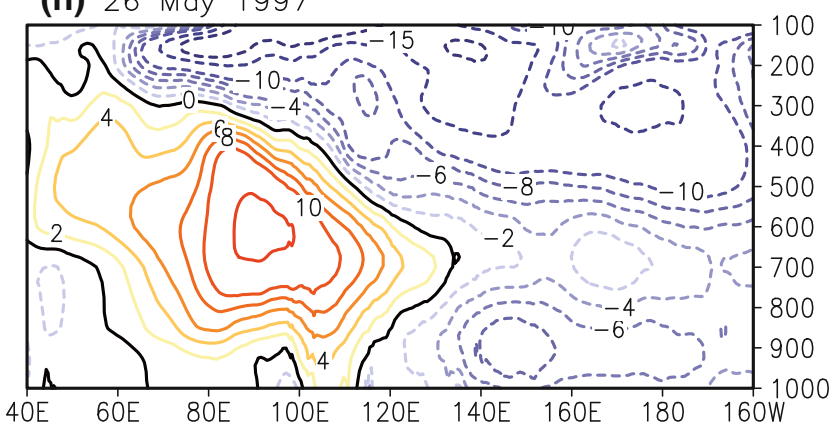

MJO in the Pacific). Right panels are from the NRCM simulation 1DOM. The black lines represent zero contours. The contour intervals are 2 between 0 and 10, and 5 afterwards. The solid (dashed) contours show positive (negative) values 
Obs

(a) 2 Nov 2000

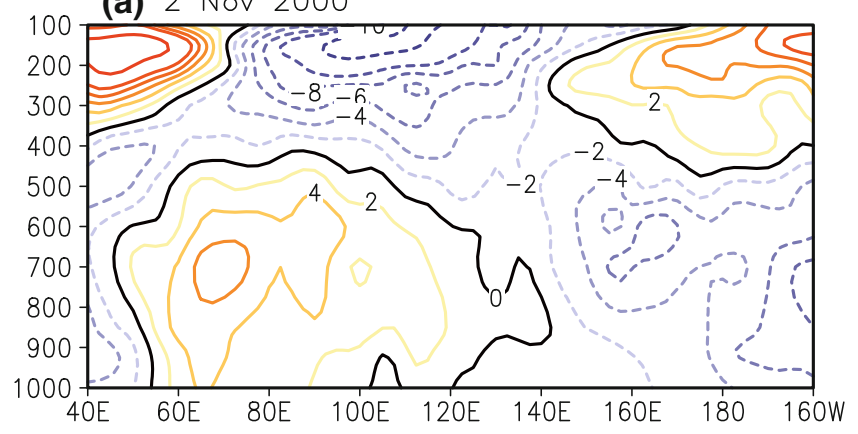

(b) 15 Nov 2000

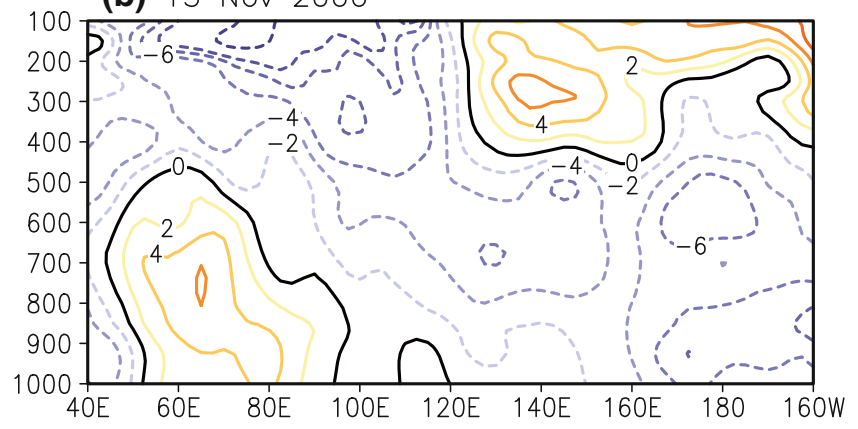

(c) 22 Nov 2000

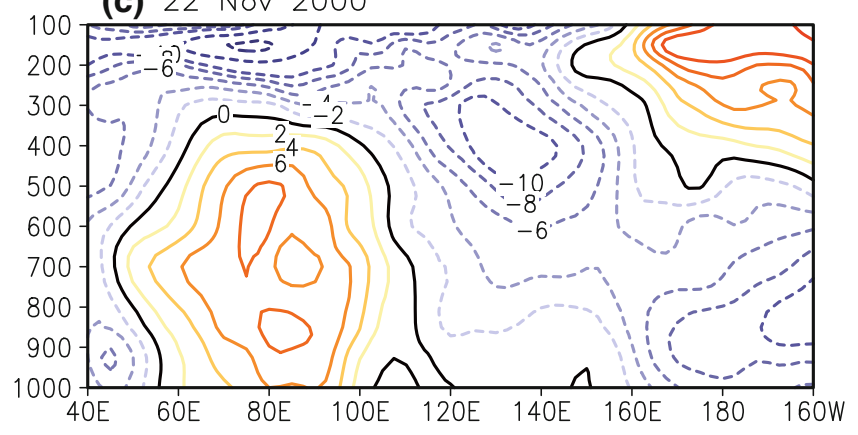

(d) $5 \mathrm{Dec} 2000$

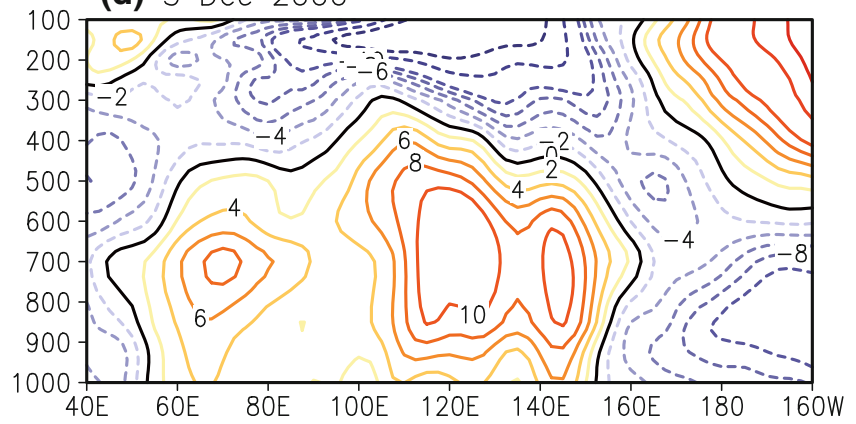

Fig. 17 Left: Vertical structure of zonal winds $\left(\mathrm{m} \mathrm{s}^{-1}\right.$, averaged over $5^{\circ} \mathrm{S}-5^{\circ} \mathrm{N}, 3$-day mean centered at the time shown above each panel) from the reanalysis for Case 2 during a November 2 (prior to the MJO initiation), b November 15 (at the initiation of the MJO), c November 22 (active phase of the MJO in the Indian Ocean), and d December 5
$1 \mathrm{DOM}$

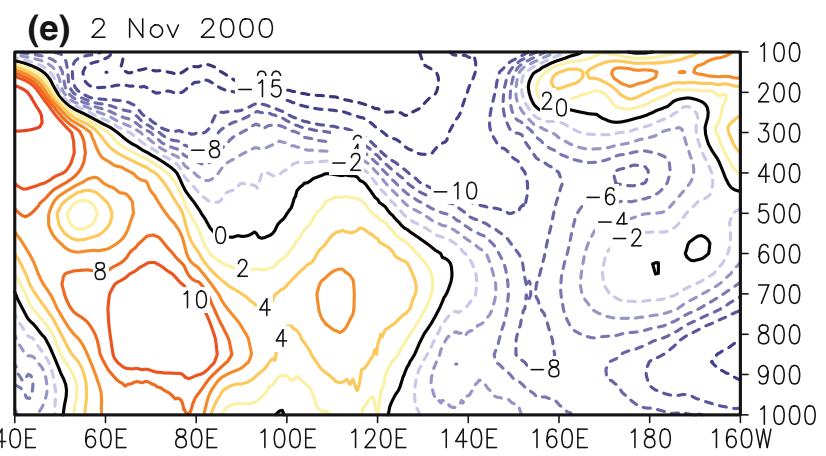

(f) $15 \mathrm{Nov} 2000$

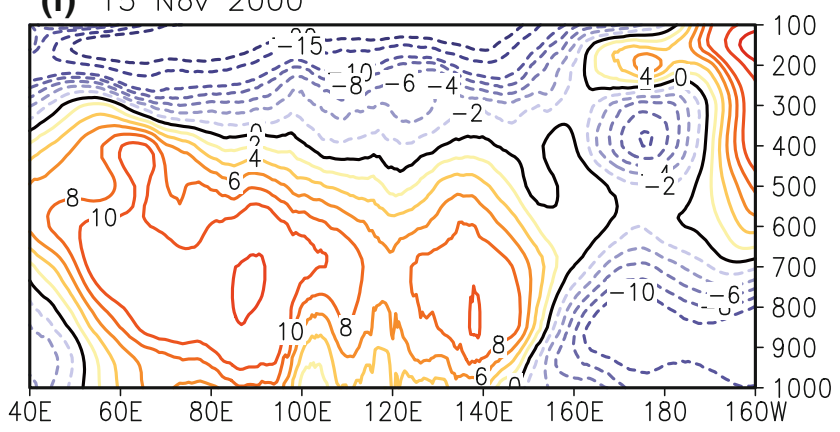

(g) 22 Nov 2000

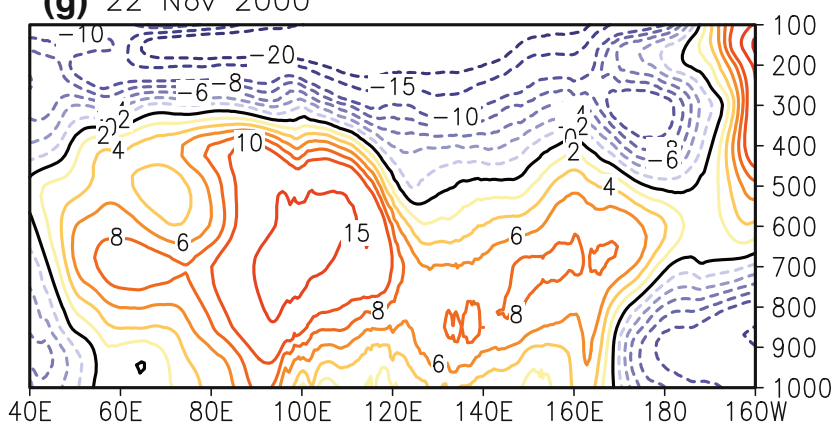

(h) $5 \mathrm{Dec} 2000$

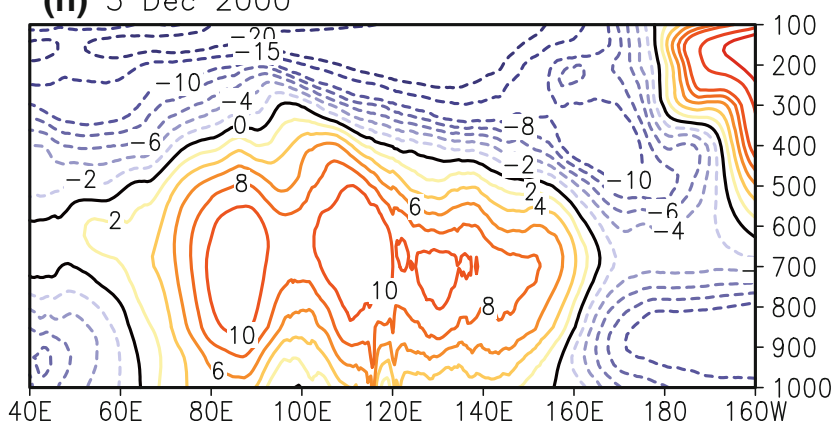

(active phase of the MJO in the Pacific). Right panels are from the NRCM simulation 1DOM. The black lines represent zero contours. The contour intervals are 2 between 0 and 10, and 5 afterwards. The solid (dashed) contours show positive (negative) values 


\section{Conclusion}

A tropical channel model (TCM) is constructed at the NCAR based on WRF (known as Nested Regional Climate Model or NRCM) and is conceptually similar to the TCM developed at the University of Miami based on MM5 (tropical MM5 or TMM5). Both TCMs are useful tools for studying the MJO.

With the initial and lateral boundary conditions provided by a global reanalysis, the WRF-based tropical channel model is integrated for several years. The simulated MJO statistics are no better than those found in the GCMs, due mainly to the error in the mean state. However, the multiyear simulation with large error in the mean state is able to capture two individual MJO events that were previously shown to be initiated by extratropical influences. On the other hand, the model is not able to simulate a third event, whose initiation was not directly influenced by the lateral boundary conditions. To further explore this event (Case 3 ), we perform several shorter sensitivity tests to understand the reasons behind the poor MJO statistics. While these simulations are far from perfect, the gross features of Case 3 are reproduced when the model is initialized during or soon after the MJO initiation. No clear MJO is reproduced when the simulation is started 2 weeks before the observed MJO initiation. A higher-resolution nested domain covering the Indo-Pacific warm pool region and including a cloud-system resolving domain over the Indonesian Maritime Continent has very little effect on the MJO initiation over the Indian Ocean. The simulations also show that the MJO initiation for Case 3 is insensitive to cumulus schemes and SST.

Further analysis reveals that the errors in the mean state in the sensitivity tests reach the errors in the longer simulation (or the "climate error" in the tropical channel model) within 1-2 weeks depending on the variables concerned. This result is in agreement with the similarity between weather error and climate error conducted as part of Climate Change Prediction Program-ARM Parameterization Testbed of the Program for Climate Model Diagnostics and Intercomparison (PCMDI) at the Livermore National Laboratory (Boyle et al. 2008). In the absence of direct dynamical influences from the meriodional boundary conditions on MJO initiation as in Case 3, the errors in the mean state prevent the MJO initiation in the simulations that are integrated 2 weeks before the MJO initiation over the Indian Ocean. In other words, the negative effect of mean state error can be overcome if there are extra dynamical influences, either from the meridional boundary conditions or initial conditions.

Our main conclusions are based on three MJO events with emphasis on one event where we argue that the error in the mean state is sufficient to prevent the MJO initiation.
No general conclusions should be drawn based on this small sample size. A systematic study is necessary to assess the role of the mean state on statistically meaningful set of observed MJO events. Such an effort is planned within the WCRP-WWRP/THORPEX coordinated project, the Year of Tropical Convection (YOTC; Moncrieff et al. 2007; Waliser and Moncrieff 2008; http://www.ucar.edu/yotc).

In conclusion, this study has presented an approach for diagnosing a model's capability to simulate MJO statistics by utilizing the simulations of the individual MJO events. This approach is effective and viable, and a complement to the multiple, multi-year simulations of the high-resolution simulations that are not always feasible. The error in the mean state is found to be important (relatively unimportant) for the initiation of the MJO in the absence (presence) of dynamical control from the lateral boundary conditions. The results call for further research attention towards using the untapped potential of high-resolution models in the MJO simulation and forecasting.

Acknowledgments Acknowledgment is made to the National Center for Atmospheric Research (NCAR), which is sponsored by the National Science Foundation, for making the model output available for this research. Computational resources provided by the NCAR are also appreciated. We thank Bill Kuo, Sherrie Fredrick, and other team members of the NRCM group. P.R. acknowledges the graduate student fellowship offered by the NCAR's ASP program. The NCEPNCAR reanalysis data were taken from NOAA/CDC. The NCEP 'FNL' data were taken from NCAR's mass storage. This study was partially supported by NSF grants ATM9912297 and ATM0739402.

\section{References}

Agudelo PA, Curry JA, Hoyos CD, Webster PJ (2006) Transition between suppressed and active phases of intraseasonal oscillations in the Indo-Pacific warm pool. J Clim 19:5519-5530

Agudelo PA, Hoyos CD, Webster PJ, Curry JA (2009) Application of a serial extended forecast experiment using the ECMWF model to interpret the predictive skill of tropical intraseasonal variability. Clim Dyn. doi:10.1007/s00382-008-0447-x

Ajayamohan RS, Goswami BN (2007) Dependence of simulation of boreal summer tropical intraseasonal oscillations on the simulation of seasonal mean. J Atmos Sci 64:460-478

Betts AK, Miller MJ (1986) A new convective adjustment scheme, II. Single column testing using GATE wave, BOMEX, ATEX, and arctic air-mass data sets. Quart J Roy Meteor Soc 112:693709

Blade I, Hartmann DL (1993) Tropical intraseasonal oscillation in a simple nonlinear model. J Atmos Sci 50:2922-2939

Boyle J, Klein S, Zhang G, Xie S, Wei X (2008) Climate model forecast experiments for TOGA COARE. Mon Weav Rev 136:808-832

Chen F, Dudhia J (2001) Coupling an advanced land surfacehydrology model with the Penn State-NCAR MM5 modeling system, part I: model implementation and sensitivity. Mon Weav Rev 129:569-585

Collins WD, Bitz CM, Blackmon ML, Bonan GB, Bretherton CS, Carton JA, Chang P, Doney SC, Hack JJ, Henderson TB, Kiehl JT, Large WG, McKenna DS, Santer BD, Smith RD 
(2006) The community climate system model: CCSM3. J Clim 19:2122-2143

Grabowski WW, Moncrieff MW (2001) Large-scale organization of tropical convection in two-dimensional explicit numerical simulations. Quart J Roy Meteor Soc 127:445-468

Gustafson WI, Weare BC (2004a) MM5 modeling of the MaddenJulian oscillation in the Indian and west Pacific Oceans: model description and control run results. J Clim 17:1320-1337

Gustafson WI, Weare BC (2004b) MM5 modeling of the MaddenJulian oscillation in the Indian and west Pacific oceans: implications of 30-70 day boundary effects on MJO development. J Clim 17:338-1351

Hayashi Y (1979) A generalized method of resolving transient disturbances into standing and traveling waves by space-time spectral analysis. J Atmos Sci 36:1017-1029

Hendon HH (2000) Impact of air-sea coupling on the Madden-Julian oscillation in a general circulation model. J Atmos Sci 57:39393952

Hong S-Y, Dudhia J, Chen S-H (2004) A revised approach to ice microphysical processes for the bulk parameterization of clouds and precipitation. Mon Weav Rev 132:103-120

Hong S-Y, Noh Y, Dudhia J (2006) A new diffusion package with an explicit treatment of entrainment processes. Mon Weav Rev 134:2318-2341

Inness PM, Slingo JM (2003) Simulation of the Madden-Julian oscillation in a coupled general circulation model. Part I: comparisons with observations and an atmosphere-only GCM. J Clim 16:345-364

Inness PM, Slingo JM, Woolnough SJ, Neale RB, Pope VD (2001) Organization of tropical convection in a GCM with varying vertical resolution; implications for the simulation of the Madden-Julian oscillation. Clim Dyn 17:777-793

Inness PM, Slingo JM, Guilyardi E, Cole J (2003) Simulation of the Madden-Julian oscillation in a coupled general circulation model. Part II: the role of the basic state. J Clim 16:365-382

Janjic ZI (1994) The step-mountain coordinate model: further development of the convection, viscous sublayer, and turbulence closure schemes. Mon Weav Rev 122:927-945

Jones C, Waliser DE, Schemm JKE, Lau WKM (2000) Prediction skill of the Madden-Julian oscillation in dynamical extended range forecasts. Clim Dyn 16:273-289

Kain JS (2004) The Kain-Fritsch convective parameterization: an update. J Appl Meteorol 43:170-181

Kalnay E et al (1996) The NCEP-NCAR 40-year reanalysis project. Bull Amer Meteor Soc 77:437-471

Kemball-Cook SR, Weare BC (2001) The onset of convection in the Madden-Julian oscillation. J Clim 14:780-793

Lau KM, Waliser DE (2005) Intraseasonal variability in the atmosphere-ocean climate system. Praxis, Chichester, UK, p 436

Lin J-L et al (2006) Tropical intraseasonal variability in 14 IPCC AR4 climate models. Part I: convective signals. J Clim 19:2665-2690

Madden RA, Julian PR (1971) Detection of a 40-50 day oscillation in the zonal wind in the tropical Pacific. J Atmos Sci 28:702-708

Madden RA, Julian PR (1972) Description of global-scale circulation cells in the tropics with a 40-50 day period. J Atmos Sci 29:1109-1123

Majda AJ, Biello JA (2004) A multiscale model for tropical intraseasonal oscillation. Proc Natl Acad Sci USA 101:47364741

Maloney ED (2009) The moist static energy budget of a composite tropical intraseasonal oscillation in a climate model. J Clim 22:711-729

Maloney ED, Hartman DL (2001) The sensitivity of intraseasonal variability in the NCAR CCM3 to changes in convective parameterization. J Clim 14:2015-2034
Matthews AJ (2008) Primary and successive events in the MaddenJulian oscillation. Quart J Roy Meteor Soc 134:439-453

McPhaden MJ (1999) Genesis and evolution of the 1997-98 El Nino. Science 283:950-954

Miura H, Satoh M, Nasuno T, Noda AT, Oouchi K (2007) A MaddenJulian oscillation event realistically simulated by a global cloudresolving model. Science 318:1763-1765

Moncrieff MW (2004) Analytic representation of the large-scale organization of tropical convection. J Atmos Sci 61:1521-1538

Moncrieff MW, Shapiro M, Slingo J, Molteni F (2007) Collaborative research at the intersection of weather and climate. WMO Bull 56:204-211

Monier E, Weare BC, Gustafson WI (2009) The Madden-Julian oscillation wind-convection coupling and the role of moisture processes in the MM5 model. Clim Dyn. doi:10.1007/ s00382-009-0626-4

North GR, Bell TL, Cahalan RF, Moeng FJ (1982) Sampling errors in the estimation of empirical orthogonal functions. Mon Weav Rev 110:699-710

Pegion K, Kirtman BP (2008a) The impact of air-sea interactions on the simulation of tropical intraseasonal variability. J Clim 21:6616-6635

Pegion K, Kirtman BP (2008b) The impact of air-sea interactions on the predictability of tropical intraseasonal variability. J Clim 21:5870-5886

Ray P (2008) The initiation of the Madden-Julian oscillation. Ph.D. Thesis, Rosenstiel School of Marine and Atmospheric Sciences, University of Miami, pp 186

Ray P, Zhang C (2010) A case study of the mechanics of extratropical influence on the initiation of the Madden-Julian oscillation. J Atmos Sci 67:515-528

Ray P, Zhang C, Dudhia J, Chen SS (2009) A numerical case study on the initiation of the Madden-Julian oscillation. J Atmos Sci 66:310-331

Raymond DJ, Torres DJ (1998) Fundamental moist modes of the equatorial troposphere. J Atmos Sci 55:1771-1790

Salby ML, Hendon HH (1994) Intraseasonal behavior of clouds, temperature, and winds in the tropics. J Atmos Sci 51:2207-2224

Slingo JM et al (1996) Intraseasonal oscillations in 15 atmospheric general circulation models: results from an AMIP diagnostic subproject. Clim Dyn 12:325-357

Sperber KP, Gualdi S, Legutke S, Gayler V (2005) The MaddenJulian oscillation in ECHAM4 coupled and uncoupled general circulation models. Clim Dyn 25:117-140

Straub KH, Kiladis GN (2002) Observations of a convectively coupled Kelvin wave in the eastern Pacific ITCZ. J Atmos Sci 59:30-53

Taylor KE, Williamson D, Zwiers F (2000) The sea surface temperature and sea-ice concentration boundary conditions for AMIP II simulations. PCMDI report no. 60 and UCRL-MI125597, pp 25

Tulich SN, Kiladis GN, Parker AS (2010) Convectively-coupled Kelvin and easterly waves in a regional climate simulation of the tropics. Clim Dyn. doi:10.1007/s00382-009-0697-2

Vitart F, Woolnough SJ, Balmaseda MA, Tompkins AM (2007) Monthly forecast of the Madden-Julian oscillation using a coupled GCM. Mon Weav Rev 135:2700-2715

Waliser DE, Moncrieff MW (2008) Year of tropical convection (YOTC) science plan, WMO/TD-no. 1452, WCRP-130, WWRP/ THORPEX, No 9, pp 26

Waliser DE, Lau KM, Kim JH (1999) The influence of coupled sea surface temperature on the Madden-Julian oscillation: a model perturbation experiment. J Atmos Sci 56:333-358

Waliser DE, Lau KM, Stern W, Jones C (2003) Potential predictability of the Madden-Julian oscillation. Bull Amer Meteor Soc $84: 33-50$ 
Wang B, Li T (1994) Convective interaction with boundarylayer dynamics in the development of the tropical intraseasonal system. J Atmos Sci 51:1386-1400

Wang WQ, Schlesinger ME (1999) The dependence of convective parameterization of the tropical intraseasonal oscillation simulated by the Uiuc 11-layer atmospheric GCM. J Clim 12:14231457

Wedi NP, Smolarkiewicz PK (2010) A nonlinear perspective on the dynamics of the MJO: idealized large-eddy simulations. J Atmos Sci 67:1202-1217

Woolnough SJ, Vitart F, Balmaseda M (2007) The role of the ocean in the Madden-Julian oscillation: sensitivity of an MJO forecast to ocean coupling. Quart J Royal Meteor Soc 133:117-128

Xie P, Arkin PA (1997) Global precipitation: a 17-year monthly analysis based on gauge observations, satellite estimates, and numerical model outputs. Bull Amer Meteor Soc 78:2539-2558
Zeng X, Beljaars A (2005) A prognostic scheme of sea surface skin temperature for modeling and data assimilation. Geophys Res Lett 32:L14605. doi:10.1029/2005GL023030

Zhang C (2005) Madden-Julian oscillation. Rev Geophys 43, RG2003. doi:10.1029/2004RG000158

Zhang C, Dong M (2004) Seasonality of the Madden-Julian oscillation. J Clim 17:3169-3180

Zhang C, Dong M, Gualdi S, Hendon HH, Maloney ED, Marshall A, Sperber KR, Wang W (2006) Simulations of the Madden-Julian oscillation by four pairs of coupled and uncoupled global models. Clim Dyn. doi:10.1007/s00382-006-0148-2

Zheng Y, Waliser DE, Stern WF, Jones C (2004) The role of coupled sea surface temperatures in the simulation of the tropical intraseasonal oscillation. J Clim 17:4109-4134 